\title{
Functional insights from the GC-poor genomes of two aphid parasitoids, Aphidius ervi and Lysiphlebus fabarum
}

Alice B. Dennis ${ }^{1,2,3^{*+}} \mathbb{D}^{\mathbb{D}}$, Gabriel I. Ballesteros ${ }^{4,5,6 \dagger}$, Stéphanie Robin ${ }^{7,8}$, Lukas Schrader ${ }^{9}$, Jens Bast ${ }^{10,11}$, Jan Berghöfer ${ }^{9}$, Leo W. Beukeboom ${ }^{12}$, Maya Belghazi ${ }^{13}$, Anthony Bretaudeau ${ }^{7,8}$, Jan Buellesbach ${ }^{9}$, Elizabeth Cash ${ }^{14}$, Dominique Colinet ${ }^{15}$, Zoé Dumas ${ }^{10}$, Mohammed Errbii ${ }^{9}$, Patrizia Falabella ${ }^{16}$, Jean-Luc Gatti ${ }^{15}$, Elzemiek Geuverink ${ }^{12}$, Joshua D. Gibson ${ }^{14,17}$, Corinne Hertaeg ${ }^{1,18}$, Stefanie Hartmann ${ }^{3}$, Emmanuelle Jacquin-Joly ${ }^{19}$, Mark Lammers ${ }^{9}$, Blas I. Lavandero ${ }^{6}$, Ina Lindenbaum ${ }^{9}$, Lauriane Massardier-Galata ${ }^{15}$, Camille Meslin ${ }^{19}$, Nicolas Montagné ${ }^{19}$, Nina Pak ${ }^{14}$, Marylène Poirié ${ }^{15}$, Rosanna Salvia ${ }^{16}$, Chris R. Smith ${ }^{20}$, Denis Tagu ${ }^{7}$, Sophie Tares ${ }^{15}$, Heiko Vogel ${ }^{21}$, Tanja Schwander ${ }^{10}$, Jean-Christophe Simon ${ }^{7}$, Christian C. Figueroa ${ }^{4,5}$, Christoph Vorburger ${ }^{1,2}$, Fabrice Legeai ${ }^{7,8}$ and Jürgen Gadau ${ }^{9^{*}}$

\begin{abstract}
Background: Parasitoid wasps have fascinating life cycles and play an important role in trophic networks, yet little is known about their genome content and function. Parasitoids that infect aphids are an important group with the potential for biological control. Their success depends on adapting to develop inside aphids and overcoming both host aphid defenses and their protective endosymbionts.

Results: We present the de novo genome assemblies, detailed annotation, and comparative analysis of two closely related parasitoid wasps that target pest aphids: Aphidius ervi and Lysiphlebus fabarum (Hymenoptera: Braconidae: Aphidiinae). The genomes are small (139 and $141 \mathrm{Mbp}$ ) and the most AT-rich reported thus far for any arthropod (GC content: 25.8 and 23.8\%). This nucleotide bias is accompanied by skewed codon usage and is stronger in genes with adult-biased expression. AT-richness may be the consequence of reduced genome size, a near absence of DNA methylation, and energy efficiency. We identify missing desaturase genes, whose absence may underlie mimicry in the cuticular hydrocarbon profile of $L$. fabarum. We highlight key gene groups including those underlying venom composition, chemosensory perception, and sex determination, as well as potential losses in immune pathway genes.
\end{abstract}

Conclusions: These findings are of fundamental interest for insect evolution and biological control applications. They provide a strong foundation for further functional studies into coevolution between parasitoids and their hosts. Both genomes are available at https://bipaa.genouest.org.

Keywords: Parasitoid wasp, Aphid host, Aphidius ervi, Lysiphlebus fabarum, GC content, de novo genome assembly, DNA methylation loss, Chemosensory genes, Venom proteins, Toll and Imd pathways

\footnotetext{
*Correspondence: alicebdennis@gmail.com; gadauj@uni-muenster.de

${ }^{\dagger}$ Alice B. Dennis and Gabriel I. Ballesteros contributed equally to this work.

1 Department of Aquatic Ecology, Eawag, 8600 Dübendorf, Switzerland

Institute for Evolution and Biodiversity, Universität Münster, Münster,

Germany

Full list of author information is available at the end of the article
}

(c) The Author(s). 2020 Open Access This article is licensed under a Creative Commons Attribution 4.0 International License, which permits use, sharing, adaptation, distribution and reproduction in any medium or format, as long as you give appropriate credit to the original author(s) and the source, provide a link to the Creative Commons licence, and indicate if changes were made. The images or other third party material in this article are included in the article's Creative Commons licence, unless indicated otherwise in a credit line to the material. If material is not included in the article's Creative Commons licence and your intended use is not permitted by statutory regulation or exceeds the permitted use, you will need to obtain permission directly from the copyright holder. To view a copy of this licence, visit http://creativecommons.org/licenses/by/4.0/ The Creative Commons Public Domain Dedication waiver (http://creativecommons.org/publicdomain/zero/1.0/) applies to the data made available in this article, unless otherwise stated in a credit line to the data. 


\section{Background}

Parasites are ubiquitously present across all of life [1, $2]$. Their negative impact on host fitness can impose strong selection on hosts to resist, tolerate, or escape potential parasites. Parasitoids are a special group of parasites whose successful reproduction is fatal to the host [3, 4]. The overwhelming majority of parasitoid insects are hymenopterans that parasitize other terrestrial arthropods, and they are estimated to comprise up to $75 \%$ of the species-rich insect order Hymenoptera [4-7]. Parasitoid wasps target virtually all insects and developmental stages (eggs, larvae, pupae, and adults), including other parasitoids [4, 8-10]. Parasitoid radiations appear to have coincided with those of their hosts [11], and there is ample evidence that host-parasitoid relationships impose strong reciprocal selection, promoting a dynamic process of antagonistic coevolution [12-14].

Parasitoids of aphids play an economically important role in biological pest control $[15,16]$, and aphidparasitoid interactions are an excellent model to study antagonistic coevolution, specialization, and speciation $[17,18]$. While parasitoids that target aphids have evolved convergently several times, their largest radiation is found in the braconid subfamily Aphidiinae, which contains at least 400 described species across 50 genera $[9,19]$. As koinobiont parasitoids, their development progresses initially in still living, feeding, and developing hosts, and ends with the aphids' death and the emergence of adult parasitoids. Parasitoids increase their success with a variety of strategies, including host choice [20,21], altering larval development timing [22], injecting venom during stinging and oviposition, and developing special cells called teratocytes to circumvent host immune responses [23-27]. In response to strong selection imposed by parasitoids, aphids have evolved numerous defenses, including behavioral strategies [28], immune defenses [29], and symbioses with heritable endosymbiotic bacteria whose integrated phages can produce toxins to hinder parasitoid success [12, 30, 31].

The parasitoid wasps Lysiphlebus fabarum and Aphidius ervi (Braconidae: Aphidiinae) are closely related endoparasitoids of aphids (Fig. 1) [9, 11, 38]. In the wild, both species are found infecting a wide range of aphid species although their host ranges differ, with $A$. ervi more specialized on aphids in the Macrosiphini tribe and L. fabarum on the Aphidini tribe $[39,40]$. Experimental evolution studies in both species have shown that wild-caught populations can counter-adapt to cope with aphids and the defenses of their endosymbionts, and that the coevolutionary relationships between parasitoids and the aphids' symbionts likely fuel diversification of both parasitoids and their hosts [41-43]. While a number of parasitoid taxa are known to inject viruses and virus-like particles into their hosts, there is thus far no evidence that this occurs in parasitoids that target aphids; recent studies have identified two abundant RNA viruses in L. fabarum $[44,45]$, but whether this impacts their ability to parasitize is not yet clear.

Aphidius ervi and L. fabarum differ in several important life history traits, and are expected to have experienced different selective regimes as a result. Aphidius ervi has been successfully introduced as a biological control agent in Nearctic and Neotropic regions. Studies on both native and introduced populations of $A$. ervi have shown ongoing evolution with regard to host preferences, gene flow, and other life history components [46-49]. Aphidius ervi is known to reproduce only sexually, whereas L. fabarum is capable of both sexual and asexual reproduction. In fact, wild $L$. fabarum populations are more commonly composed of asexually reproducing (thelytokous) individuals [50], and this asexuality is not due to infection with endosymbionts like Wolbachia [51]. In asexual populations of L. fabarum, diploid females produce diploid female offspring via central fusion automixis [52]. While they are genetically differentiated, sexual and asexual populations appear to maintain gene flow; both reproductive modes and genomewide heterozygosity are maintained in the species as a whole [50, 53, 54]. Aphidius ervi and L. fabarum have also experienced different selective regimes with regard to their cuticular hydrocarbon profiles and chemosensory perception. Lysiphlebus target aphid species that are ant-tended, and ants are known to prevent parasitoid attacks on "their" aphids [55]. To counter ant defenses, L. fabarum has evolved the ability to mimic the cuticular hydrocarbon profile of the aphid hosts $[56,57]$. This enables the parasitoids to circumvent ant defenses and access this challenging ecological niche, from which they also benefit nutritionally; they are the only parasitoid species thus far documented to behaviorally encourage aphid honeydew production and consume this high-sugar reward $[55,58,59]$.

We present here the genomes of $A$. ervi and $L$. fabarum, assembled de novo using a hybrid sequencing approach. The two genomes are strongly biased towards AT nucleotides. We have examined GC content in the context of host environment, nutrient limitation, and gene expression. By comparing these two genomes, we identify key functional specificities in genes underlying venom composition, oxidative phosphorylation (OXPHOS), cuticular hydrocarbon (CHC) composition, sex determination, development (Osiris), and chemosensory perception. In both 
(a) Life cycle of aphid parasitoids

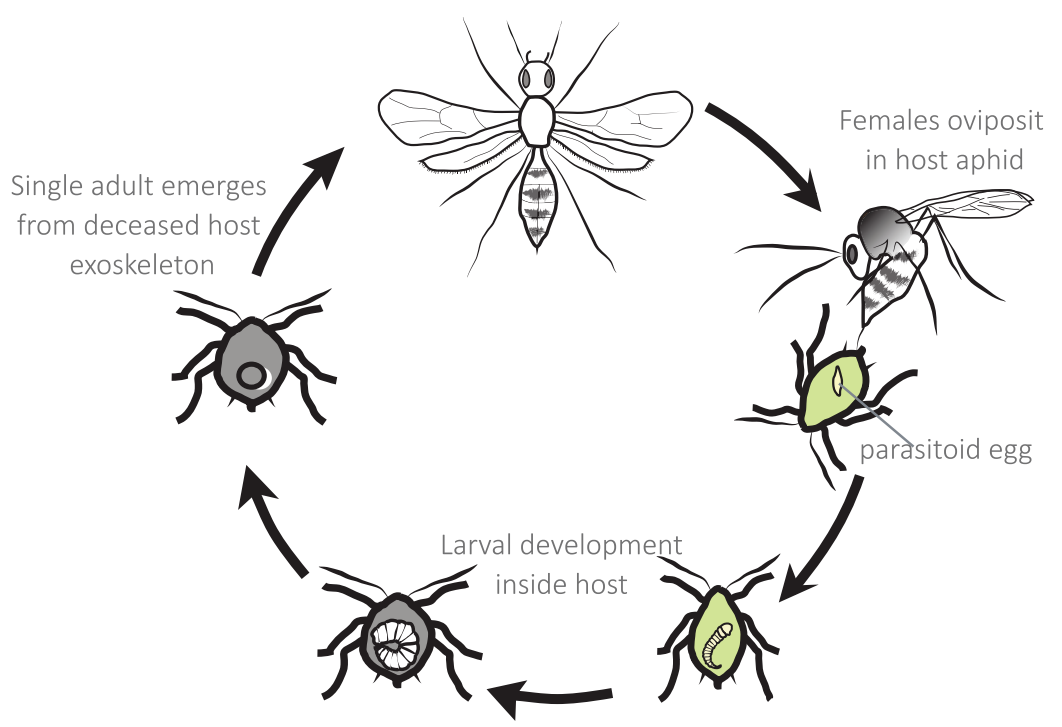

\begin{tabular}{|lll|}
\hline (b) Life history characteristics & Aphidius ervi & Lysiphlebus fabarum \\
\cline { 2 - 3 } Host insects & Aphididae & Aphididae \\
Reproductive mode & Sexual & Asexual or sexual \\
Host is ant tended & No & Yes, usually \\
Native range & Europe & Palaearctic \\
Primary host aphid tribe & Macrosiphini & Aphidini \\
\hline
\end{tabular}

(c) Phylogeny

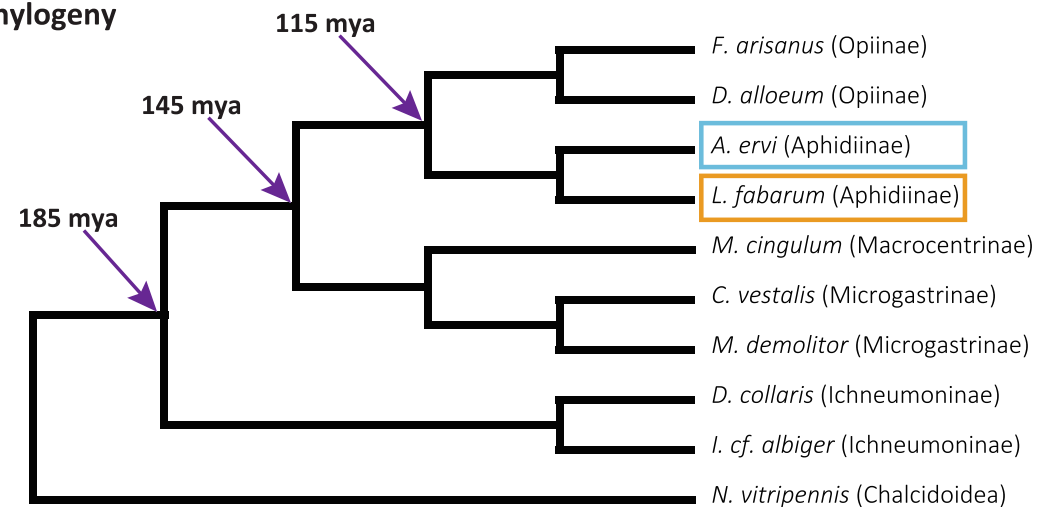

Fig. 1 Life history characteristics of two aphid parasitoids. a Generalized life cycle of Aphidius ervi and Lysiphlebus fabarum, two parasitoid wasp species that infect aphid hosts. Figure by Alice Dennis. $\mathbf{b}$ Life history characteristics of the two species. $\mathbf{c}$ Phylogenetic relationships of the Ichneumonoidea species listed in Table 2, rooted with Nasonia vitripennis (Chalcidoidea). Average divergence times between major groups and phylogenetic relationships have been modified, after Supplemental Figure S1 in [9, 11], Ichneumon cf. albiger is also included to better match dating available from [11]. The subfamily for each species is given after the species name

species, we identify putative losses in key immune genes and an apparent lack of key DNA methylation machinery. These are functionally important traits associated with success infecting aphids and the evolution of related traits across all of Hymenoptera.

\section{Results}

Two de novo genome assemblies

The genome assemblies for $A$. ervi and L. fabarum were constructed using hybrid approaches that incorporated high-coverage short read (Illumina) and long-read (Pac 
Bio) sequences, and were assembled with different strategies (Supplementary Tables 1 and 2). This produced two high quality genome assemblies (N50 in A. ervi: 581 $\mathrm{kb}$, in L. fabarum: $216 \mathrm{~kb})$ with similar total lengths $(A$. ervi: $139 \mathrm{Mbp}$, L. fabarum: 141Mbp) but different ranges of scaffold-sizes (Table 1, Supplementary Table 3). The length of these assemblies is in range of that predicted by a kmer analysis with the K-mer Analysis Toolkit (KAT) (Supplementary Figure 1) [60], which predicted $A$. ervi at $142.83 \mathrm{Mbp}$ and $L$. fabarum at $99.26 \mathrm{Mbp}$. However, the L. fabarum assembly is larger than the estimate from KAT; we suspect that this may be due to duplications in the assembly, and future work should address these duplications. These assembly lengths are also within previous estimates of $110-180 \mathrm{Mbp}$ for braconids, including A. ervi $[61,62]$ and are on par with those predicted in other hymenopteran genomes (Table 2). Both genomes were screened for potential contamination (Supplementary Figures 2 and 3, Supplementary Table 6, Additional files 1 and 2) based on BLAST [63] matches to host aphids and results of the program blobtools [64], which jointly examines GC content and sequencing depth. In addition to identifying likely bacterial scaffolds (A. ervi: 35 scaffolds/ 106Kbp removed, no scaffolds removed from L. fabarum), blobtools revealed one outlier scaffold in L. fabarum with high coverage and low GC content (tig00001511, 10,205 bp, 11.1\% GC). A BLASTn search against the NCBI $n t$ database matched this to the mitochondrial genome of Aphidius gifuensis. In this and other parasitoids, the mitochondrial genome has been shown to be highly enriched with AT repeats, with GC contents that are nearly as low as the $11.1 \%$ found in this L. fabarum scaffold (13.5-17.5\%) [65]. The assemblies

Table 1 Assembly and draft annotation statistics

\begin{tabular}{lll}
\hline & A. ervi & L. fabarum \\
\hline Assembly statistics & & \\
Total length (bp) & $138,845,131$ & $140,705,580$ \\
Longest scaffold (bp) & $3,671,467$ & $2,183,677$ \\
scaffolds & 5743 & 1698 \\
scaffolds $\geq 3000$ bp & 1503 & 1698 \\
N50 (bp) & 581,355 & 216,143 \\
GC \% & $25.8 \%$ & $23.8 \%$ \\
Annotation statistics & & \\
Exons & 95,299 & 74,701 \\
Introns & 74,971 & 59,498 \\
CDS & 20,328 & 15,203 \\
\% genome covered by CDS & $17.8 \%$ & $14.9 \%$ \\
GC \% in CDS & $31.9 \%$ & $29.8 \%$ \\
GC \% of 3rd position in CDS & $15.5 \%$ & $10.7 \%$ \\
CDS with transcriptomic support & $77.8 \%$ & $88.3 \%$ \\
\hline
\end{tabular}

are available in NCBI (PRJNA587428, SAMN131909034) and can be accessed via the BioInformatics Platform for Agroecosystem Arthropods (BIPAA, https://bipaa. genouest.org), which contains the full annotation reports, predicted genes, and can be searched via both keywords and BLAST.

We constructed linkage groups for L. fabarum using phased SNPs from the haploid sons of a single female wasp from a sexually reproducing population. This placed the 297 largest scaffolds (> 50\% of the nucleotides, Supplementary Table 7, Supplementary Figure 4, Additional file 3) onto the expected six chromosomes [52]. With this largely contiguous assembly, we identified stretches of syntenic sequence between the two genomes, with $>60 \mathrm{k}$ links in alignments made by NUCmer [66] and $>350$ large syntenic blocks that match the six L. fabarum chromosomes to 28 A. ervi scaffolds (Supplementary Figures 5 and 6).

The Maker2 annotation pipeline predicted coding genes (CDS) in both genomes separately, and these were functionally annotated against the NCBI $n r$ database [67], gene ontology (GO) terms [68, 69], and predictions for known protein motifs, signal peptides, and transmembrane domains (Supplementary Table 5). In A. ervi there were 20,328 predicted genes comprising $24.7 \mathrm{Mbp}$, whereas in L. fabarum there were 15,203 genes across $21.9 \mathrm{Mbp}$ (Table 1). Matches to the BUSCO (Benchmarking Universal Single-Copy Orthologs) genes assessed completeness against the Insecta database genes at both the nucleotide level (A. ervi: 94.8\%, L. fabarum: 76.3\%, Supplementary Table 4) and protein level in the predicted genes (A. ervi: 93.7\%, L. fabarum: 95.9\%). These protein level matches are close to those found in other assembled parasitoid genomes, which report between 96 and $99 \%$ total coverage of BUSCO genes [32-37]. In both species, there was also high transcriptomic support for the predicted genes (77.8\% in A. ervi and $88.3 \%$ in L. fabarum).

A survey of transposable Elements (TEs) identified a similar overall number of putative TE elements in the two assemblies (A. ervi: 67,695 and L. fabarum: 60,306, Supplementary Table 8). Despite this similarity, the overall coverage by repeats is larger in the assembly of $L$. fabarum $(41 \%, 58 \mathrm{Mbp})$ than in A. ervi (22\%, 31Mbp) and both assemblies differ in the TE classes that they contain (Supplementary Table 8, Supplementary Figures 7 and 8). This could be the product of their different assembly methods. However, direct estimates from unassembled short read data suggest even higher repeat content in L. fabarum $(49.1 \%$ vs. $29.3 \%$ in A. ervi), largely explained by differences in simple repeats and low-complexity sequences (Supplementary Table 9).

To examine genes that may underlie novel functional adaptation, we identified sequences that are unique within the predicted genes in the A. ervi and L. fabarum 
Table 2 Assembly summary statistics compared to other parasitoid genomes. All species are from the family Braconidae, except for N. vitripennis (Pteromalidae) and D. collaris (Ichneumonidae). Protein counts from the NCBI genome deposition

\begin{tabular}{|c|c|c|c|c|c|c|c|}
\hline Parasitoid species & Assembly & $\begin{array}{l}\text { Total Length } \\
\text { (Mbp) }\end{array}$ & $\begin{array}{l}\text { Scaffold Count } \\
\text { (N50, Kbp) }\end{array}$ & $\begin{array}{l}\text { Contig count } \\
\text { (N50, Kbp) }\end{array}$ & $\begin{array}{l}\text { Predicted genes } \\
\text { (CDS) }\end{array}$ & GC (\%) & NCBI BioProject \\
\hline Aphidius ervi & A. ervi_v3 & 138.8 & $5743(581.4)$ & $12,948(25.2)$ & 20,344 & 25.8 & This paper \\
\hline Lysiphlebus fabarum & L. fabarum_v1 & 140.7 & na & $1698(216.1)$ & 15,203 & 23.8 & This paper \\
\hline Cotesia vestalis & ASM95615v1 & 178.55 & 1437 (2609.6) & $6820(51.3)$ & 11,278 & 29.96 & PRJNA307296 [32] \\
\hline Diachasma alloeum & Dall2.0 & 384.4 & $3313(657.0)$ & $24,824(45.5)$ & na & 38.3 & PRJNA284396 [33. \\
\hline Fopius arisanus & ASM80636v1 & 153.6 & $1042(980.0)$ & $8510(51.9)$ & 18,906 & 39.4 & PRJNA258104 [34 \\
\hline Macrocentrus cingulum & MCINOGS1.0 & 132.36 & $5696(192.4)$ & $13,289(64.9)$ & 11,993 & 35.66 & PRJNA361069 [35. \\
\hline Microplitis demolitor & Mdem 2 & 241.2 & $1794(1140)$ & $27,508(14.12)$ & 18,586 & 33.1 & PRJNA251518 [36. \\
\hline Diadromus collaris & ASM939471v1 & 399.17 & 2731 (1030.3) & $20,676(25,941)$ & 15,328 & 37.37 & PRJNA307299 [32 \\
\hline Nasonia vitripennis & Nvit_2.1 & 295.7 & $6169(709)$ & $26,605(18.5)$ & 24,891 & 40.6 & PRJNA13660 [37] \\
\hline
\end{tabular}

genomes. We defined these orphan genes as predicted genes with transcriptomic support and with no identifiable homology based on searches against the NCBI $n r$, $n t$, and Swissprot databases. We identified 2568 (A. ervi, Additional file 4) and 968 (L. fabarum, Additional file 5) putative orphans.

\section{GC content}

The L. fabarum and A. ervi genomes are the most GCpoor of insect genomes sequenced to date (GC content: 25.8 and $23.8 \%$ for $A$. ervi and L. fabarum, respectively, Table 1, Supplementary Figure 9, Additional file 6). This nucleotide bias is accompanied by strong codon bias in the predicted genes, meaning that within the possible codons for each amino acid, the two genomes are almost universally skewed towards the codon(s) with the lowest GC content (measured as Relative Synonymous Codon Usage, RSCU, Fig. 2). We examined potential constraints in codon usage between our two species' genomes and taxa associated with this parasitoid-host-endosymbiont system (Supplementary Table 10). We found no evidence of similarity in codon usage (scaled as RSCU) nor nitrogen content (scaled per amino acid) between parasitoids and host aphids, the primary endosymbiont Buchnera, or the secondary endosymbiont Hamiltonella (Supplementary Figures 10, 11 and 12).

As selective pressure for translational efficiency, stability, and secondary structure should be higher in more highly expressed genes [70-73], we examined GC content in relation to expression level. We first explored constraints by looking at overall expression levels. In both species, the most highly expressed $10 \%$ of genes had significantly higher GC and higher nitrogen contents, although the higher number of nitrogen molecules in Guanine and Cytosine means that these two measures cannot be entirely disentangled (Additional file 7, Supplementary Figure 13). This is in line with observations across many taxa, and with the idea that GC-rich mRNA has increased expression via its stability and secondary structure $[72,73]$.

We next utilized available transcriptomic data from adult and larval L. fabarum to examine life-stage specific constraints. We found higher GC content in larvaebiased genes in L. fabarum (Fig. 3). This was true when we compared both the $10 \%$ most highly expressed genes in adults (32.6\% GC) and larvae (33.2\%, $p=1.2 \mathrm{e}-116$, Fig. 3, Additional file 7), and this pattern holds even more strongly for genes that are differentially expressed between adults (upregulated in adults: $28.7 \% \mathrm{GC}$ ) and larvae (upregulated in larvae: $30.7 \% \mathrm{GC}, p=2.2 \mathrm{e}-80$ ). Note that the most highly expressed genes overlap partially with those that are differentially expressed (Additional file 7). At the same time, nitrogen content did not differ in either comparison (Fig. 3).

\section{Gene family expansions}

To examine gene families that may have undergone expansions in association with functional divergence and specialization, we identified groups of orthologous genes that have increased and decreased in size in the two genomes, relative to one another. We identified these species-specific gene-family expansions using the Orthologous MAtrix (OMA) standalone package [74]. OMA predicted 8817 OMA groups (strict 1:1 orthologs) and 


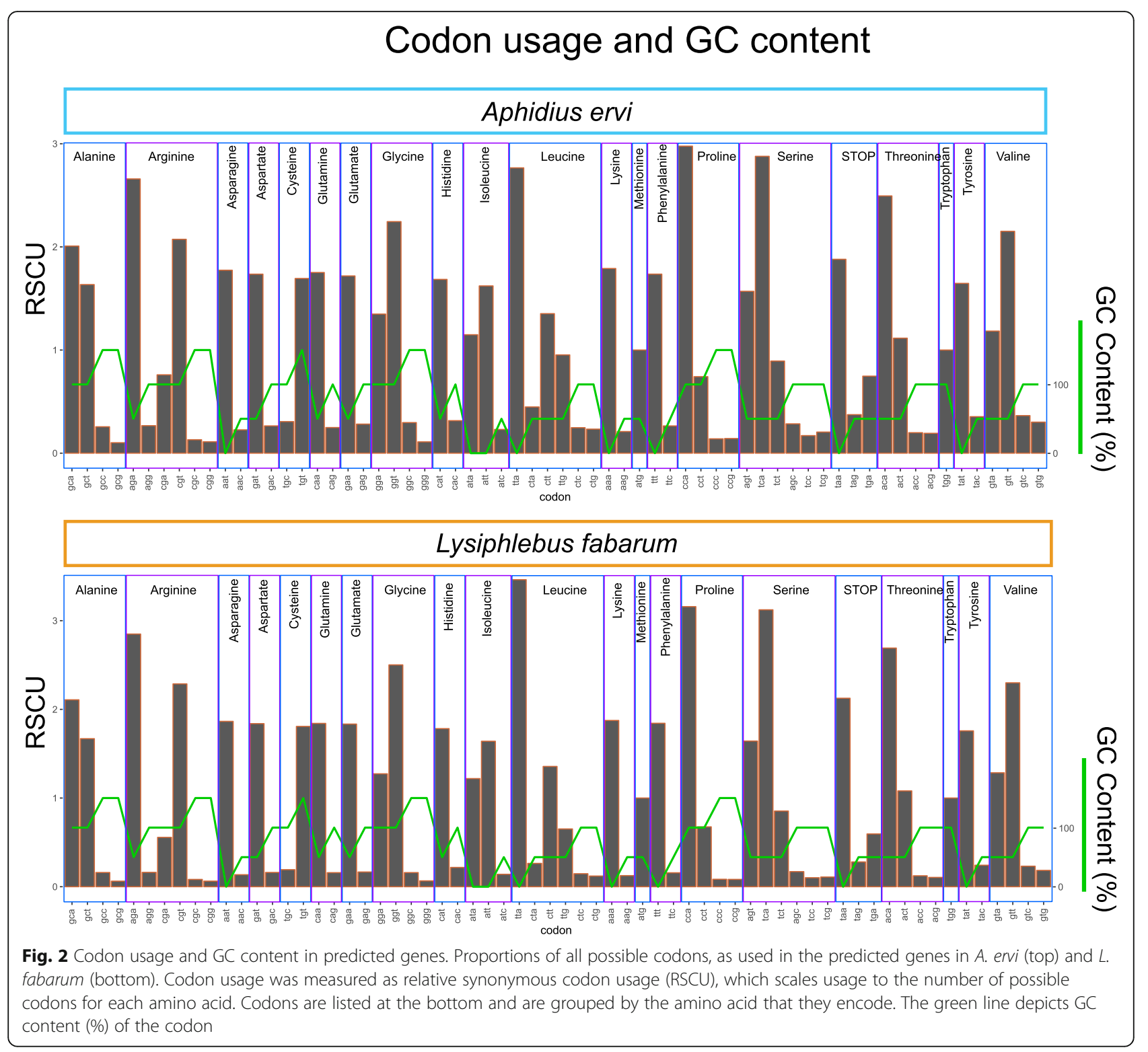

8578 Hierarchical Ortholog Groups (HOGs, Additional file 8). Putative gene-family expansions would be found in the predicted HOGs, because they are calculated to allow for $>1$ member per species. Among these, there were more groups in which $A$. ervi possessed more genes than $L$. fabarum (865 groups with more genes in A. ervi, 223 with more in L. fabarum, Supplementary Figure 14, Additional file 8). To examine only the largest gene-family expansions, we looked further at the HOGs containing $>20$ genes (10 HOG groups, Supplementary Figure 15). Strikingly, the four largest expansions were more abundant in $A$. ervi and were all identified as $\mathrm{F}$ box proteins/Leucine-rich-repeat proteins ( $L R R$, total: 232 genes in A. ervi and 68 in L. fabarum, Supplementary Figure 15, Additional file 8). This signature of expansion does not appear to be due to fragmentation in the $A$. ervi assembly; the size of scaffolds containing LRRs is on average larger in A. ervi than in L. fabarum (Welch two-sample t-test, $p=0.001$, Supplementary Figure 16). The six largest gene families that were expanded in $L$. fabarum, relative to $A$. ervi, were less consistently annotated. Interestingly, they contained two different histone proteins: Histone $\mathrm{H} 2 \mathrm{~B}$ and $\mathrm{H} 2 \mathrm{~A}$ (Supplementary Figure 15).

\section{Venom proteins}

We examined the venom of both species using evidence from proteomics, transcriptomics, and manual gene annotation. The venom gland of $L$. fabarum is morphologically different from that of $A$. ervi (Supplementary Figure 17). A total of $35 \mathrm{~L}$. fabarum proteins were identified as putative venom proteins by $1 \mathrm{D}$ gel electrophoresis and mass 


\section{Genes expressed in larval and adult $L$. fabarum}
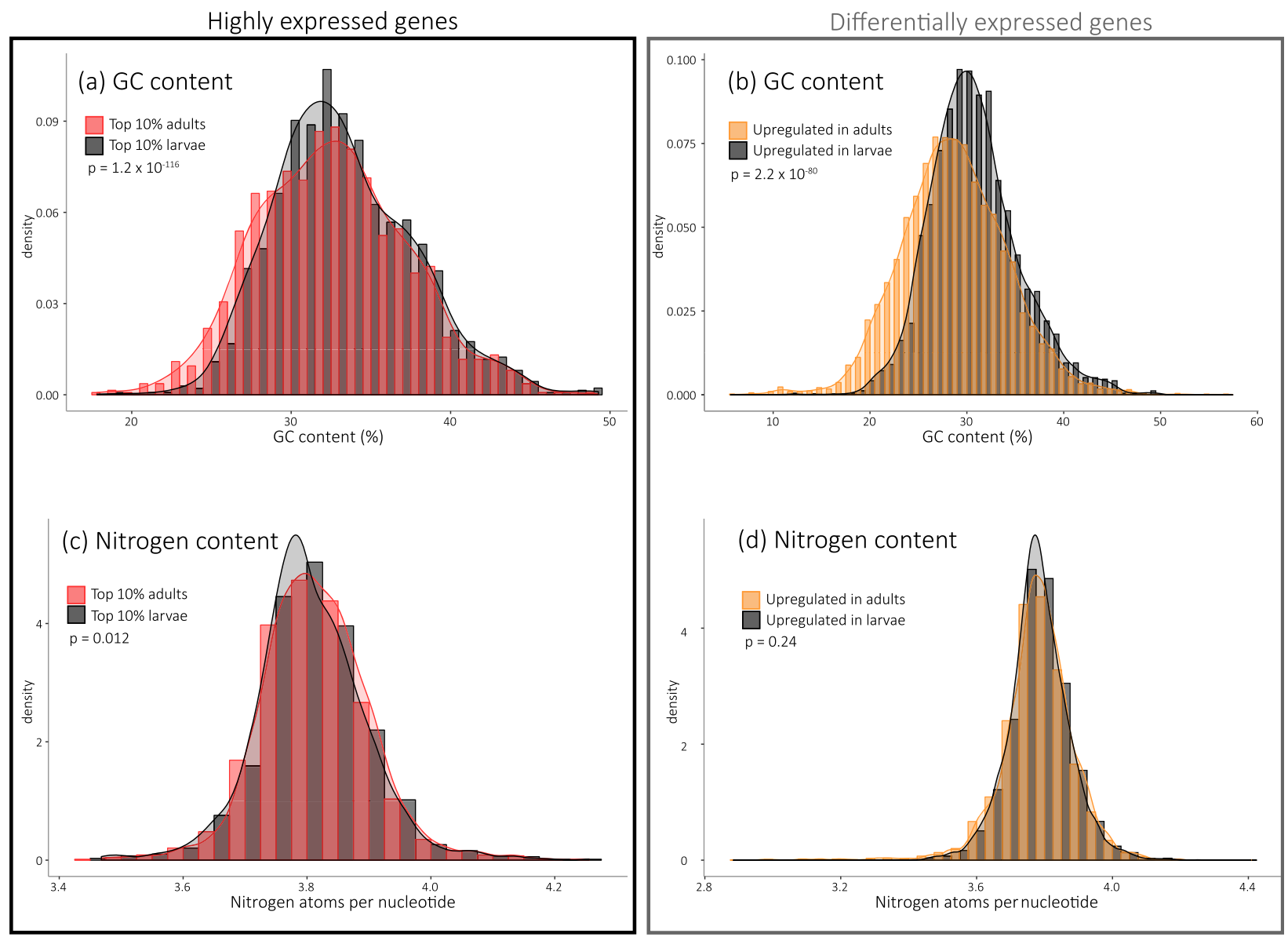

Fig. 3 GC and nitrogen content of expressed genes. We observe significant differences in the GC content of genes biased towards adult or larval L. fabarum in: (a) the 10\% most highly expressed genes and (b) genes that are significantly differentially expressed between adults and larvae. In contrast, there is no difference in the nitrogen content of the same set of genes (c, d). P-values are from a two-sided t-test

spectrometry, combined with transcriptomic and the genomic data (Supplementary Figure 18, Additional file 9) [42]. These putative venom proteins were identified based on predicted secretion (for complete sequences) and the absence of a match to typical cellular proteins (e.g. actin, myosin). To match the analysis between the two taxa, previously generated $A$. ervi venom protein data [24] were analyzed using the same criteria as for $L$. fabarum. This identified 32 putative venom proteins in $A$. ervi (Additional file 9 ). More than $50 \%$ of the proteins are shared between species (Fig. 4a and Additional file 9), corresponding to more than $70 \%$ of the predicted putative functional categories (Fig. 4b and Additional file 9). Among the venom proteins shared between both parasitoids, a gamma glutamyl transpeptidase (GGT1) was the most abundant protein in the venom of both A. ervi [24] and $L$. fabarum (Additional file 9). As previously reported for A. ervi [24], a second GGT venom protein (GGT2) containing mutations in the active site was also found in the venom of $L$. fabarum (Supplementary Figures 19 and 20).

Phylogenetic analysis (Fig. 5) showed that the A. ervi and $L$. fabarum GGT venom proteins occur in a single clade in which the GGT1 venom proteins group separately from GGT2 venom proteins, thus suggesting that they originated from a duplication that occurred prior to the split from their most recent common ancestor. As previously shown for $A$. ervi, the GGT venom proteins of $A$. ervi and $L$. fabarum are found in one of the three clades described for GGT proteins of non-venomous hymenopterans (clade "A", Fig. 5) [24]. Within this clade, venomous and non-venomous GGT proteins had a similar exon structure, except for exon 1 that corresponds to the signal peptide only being present in venomous GGT proteins (Supplementary Figure 19). Several LRR proteins were found in the venom of $L$. fabarum as well, 


\section{A. Overlap in venom proteins}

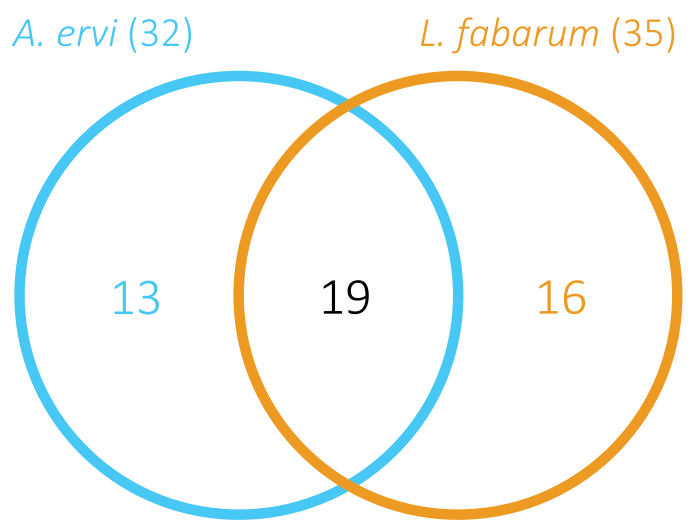

B. Overlap in venom functional categories

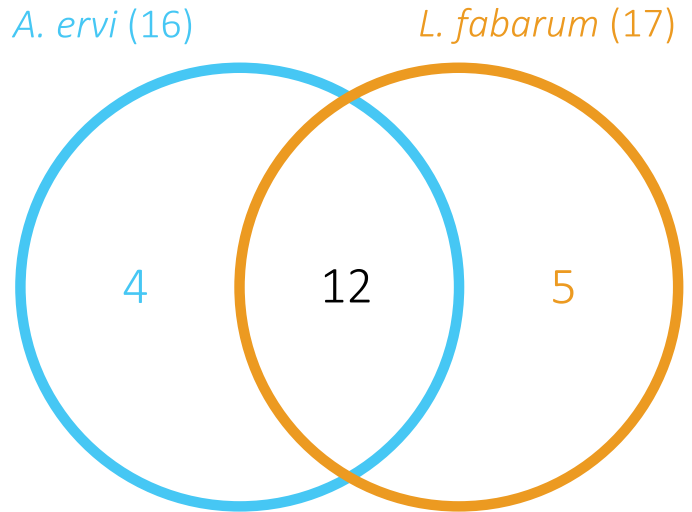

Fig. 4 Overlap in venom proteins and functional categories between A. ervi and L. fabarum. Venn diagrams show the number of (a) venom proteins and (b) venom functional categories that are shared or unique to $A$. ervi and L. fabarum

although these results should be interpreted with caution since the sequences were incomplete and the presence of a signal peptide could not be confirmed (Additional file 9). Moreover, these putative venom proteins were only identified from transcriptomic data of the venom apparatus and we could not find any corresponding annotated gene in the genome. This supports the idea that gene-family expansions in putative F-box/ $L R R$ proteins identified in the analysis with OMA are not related to venom production.

Approximately $50 \%$ of the identified venom proteins were unique to either A. ervi or L. fabarum (Additional file 9). However, many of these proteins had no predicted function, making it difficult to hypothesize their possible role in parasitism success. Among those that could be identified was apolipophorin in the venom of $L$. fabarum, but not in A. ervi. Apolipophorin is an insect- specific apolipoprotein involved in lipid transport and innate immunity, and is not commonly found in venoms. Among parasitoid wasps, apolipophorin has been described in the venom of the ichneumonid Hyposoter didymator [75] and the encyrtid Diversinervus elegans [76], but its function is yet to be deciphered. Apolipophorin is also present in low abundance in honeybee venom where it could have antibacterial activity [77, 78]. In contrast, we could not find L. fabarum homologs for any of the three secreted cysteine-rich toxinlike peptides that are highly expressed in the A. ervi venom apparatus (Additional file 9).

\section{Key gene families}

We manually annotated 719 genes in $A$. ervi and 642 in $L$. fabarum (Table 3) using Apollo, hosted on the BIPAA website: bipaa.genouest.org [79-81].

\section{Desaturases}

Annotation of desaturase genes found that L. fabarum has three fewer desaturase genes than A. ervi (Table 3, Supplementary Table 12, Supplementary Figure 24). Examination of the cuticular hydrocarbon $(\mathrm{CHC})$ profiles of $L$. fabarum and $A$. ervi identified several key differences. The $\mathrm{CHC}$ profile of $L$. fabarum is dominated by saturated hydrocarbons (alkanes), contains only trace alkenes, and is completely lacking dienes (Supplementary Figures 21 and 23). In contrast, $A$. ervi females produce a large amount of unsaturated hydrocarbons, with a substantial amount of alkenes and alkadienes in their $\mathrm{CHC}$ profiles (app. 70\% of the $\mathrm{CHC}$ profile are alkenes/alkadienes, Supplementary Figures 22 and 23).

\section{Immune genes}

We searched for immune genes in the two genomes based on a list of 373 immunity related genes, collected primarily from the Drosophila literature (Additional file 10). We found and annotated $>70 \%$ of these in both species (A. ervi: 270, L. fabarum: 264 genes). We compared these with the immune genes used to define the main Drosophila immune pathways (Toll, Imd, and JAK-STAT, Supplementary Table 13) and conserved in a number of insect species [82-84]. In the genome of both wasps, some of the genes encoding proteins of the Imd and Toll pathways were absent (Supplementary Table 13, Supplementary Figure 25, Additional file 10). Only one GNBP (Gram Negative Binding Protein) involved in Gram positive bacteria and fungi recognition was found in A. ervi and L. fabarum, compared to the three known from Drosophila and 2 from Apis (Supplementary Table 13). PGRPs (Peptidoglycan Recognition Proteins) are involved in the response to Gram-positive bacteria [85], and we did not find any significant matches to these, although two short matches did not meet our 


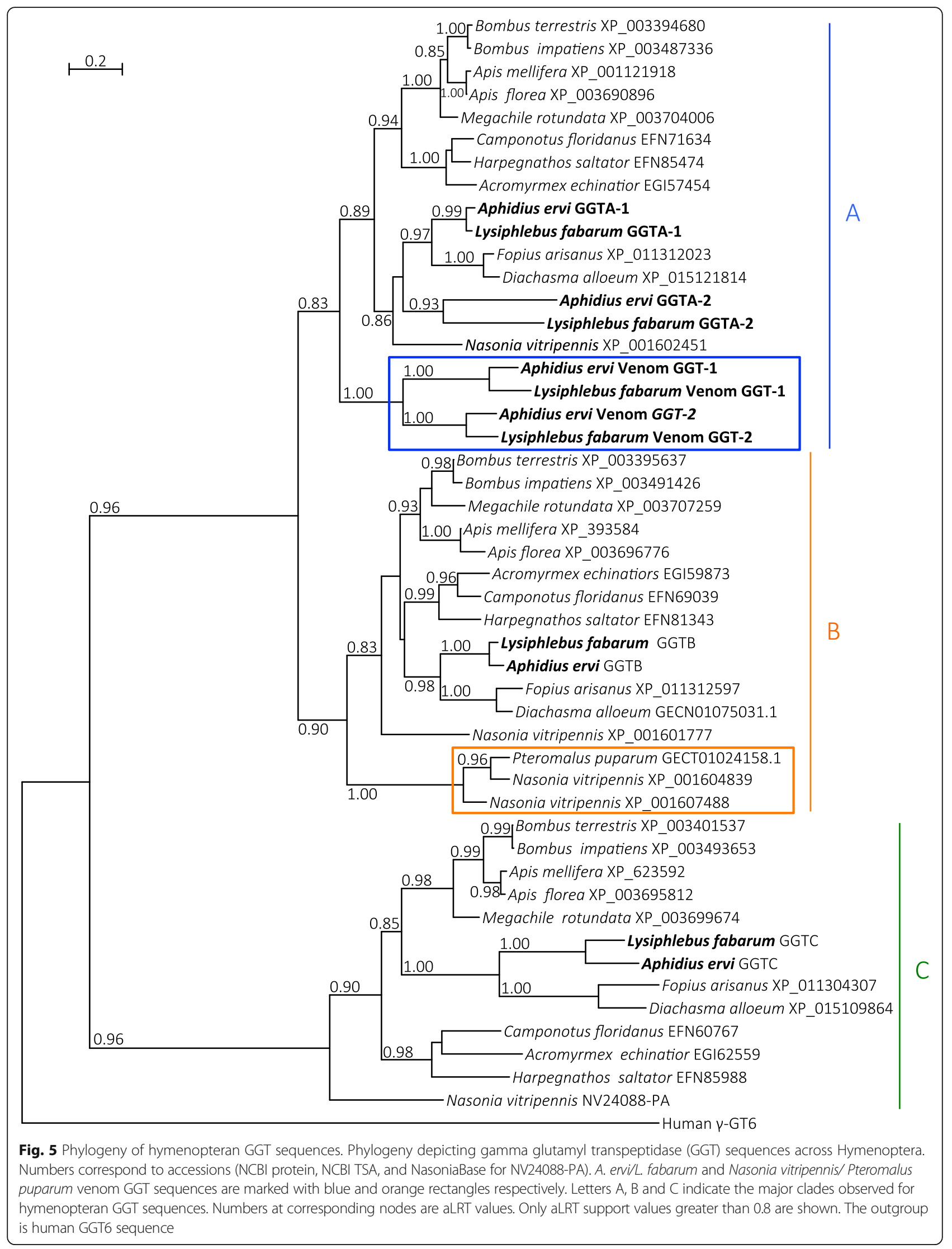


Table 3 Summary of manual curations of select gene families in the two parasitoid genomes

\begin{tabular}{lll}
\hline Category & A. ervi & L. fabarum \\
\hline Venom proteins & 32 & 35 \\
Desaturases & 14 & 11 \\
Immune genes & 270 & 264 \\
Osiris genes & 21 & 25 \\
Mitochondrial Oxidative Phosphorylation System & 75 & 74 \\
(OXPHOS) $^{\mathrm{a}}$ & & \\
Chemosensory group & & \\
Chemosensory: Odorant receptors (ORs) & 228 & 156 \\
$\begin{array}{l}\text { Chemosensory: Ionotropic chemosensory } \\
\text { receptors (IRs) }\end{array}$ & 42 & 40 \\
Chemosensory: Odorant-binding proteins (OBPs) & 14 & 14 \\
Chemosensory: Chemosensory proteins (CSPs) & 11 & 13 \\
Sex determination group & & \\
Sex determination: Core (transformer, doublesex) & 4 & 3 \\
Sex determination: Related genes & 6 & 5 \\
DNA methylation genes & 2 & 2 \\
TOTALS & $\mathbf{7 1 9}$ & $\mathbf{6 4 2}$ \\
\hline
\end{tabular}

${ }^{a}$ Note: includes possible assembly duplicates

selection criteria (blast matches $>1 \mathrm{e}-5$ ). Similarly, the only match to imd itself was very poor in $A$. ervi (evalue: 0.058 , Additional file 10), and we could not find any match in L. fabarum. The components of the Toll and JAK/Stat pathways appear to be less affected than those of the Imd pathway, although in all cases the output effectors remained mainly unknown.

\section{Osiris genes}

The Osiris genes are an insect-specific gene family that underwent multiple tandem duplications early in insect evolution. These genes are essential for proper embryogenesis [86] and pupation [87, 88], and are also tied to immune and toxin-related responses (e.g.) [87, 89] and developmental polyphenism [90, 91].

We found 21 and 25 putative Osiris genes in the A. ervi and L. fabarum genomes, respectively (Supplementary Tables 14 and 15, Supplementary Figure 26). In insects with well assembled genomes, there is a consistent synteny of approximately 20 Osiris genes; this cluster usually occurs in a $\sim 150 \mathrm{kbp}$ stretch and gene synteny is conserved in all known Hymenoptera genomes. The Osiris cluster is also largely devoid of non-Osiris genes in most of the Hymenoptera, but the assemblies of $A$. ervi and $L$. fabarum suggest that if the cluster is actually syntenic in these species, there are interspersed non-Osiris genes (black boxes in Supplementary Figures 27 and 28).

In support of their role in defense (especially metabolism of xenobiotics and immunity), these genes were much more highly expressed in larvae than in adults (Supplementary Table 15). We hypothesize that their upregulation in larvae is an adaptive response to living within a host. Because of the available transcriptomic data, we could only make this comparison in L. fabarum. Here, 19 of the 26 annotated Osiris genes were significantly upregulated in larvae over adults (Supplementary Table 15, Additional file 11). In both species, transcription in adults was very low, with fewer than 10 raw reads per cDNA library sequenced, and most often less than one read per library (Supplementary Tables 14 and 15).

\section{OXPHOS}

In most eukaryotes, mitochondria provide the majority of cellular energy (in the form of adenosine triphosphate, ATP) through the oxidative phosphorylation (OXPHOS) pathway. OXPHOS genes are an essential component of energy production, and their amino acid substitution rate in Hymenoptera is higher relative to any other insect order [92]. We identified 69 out of 71 core OXPHOS genes in both genomes, as well as five putative duplication events that are apparently not assembly errors (Supplementary Table 16, Additional file 12). The gene sets of $A$. ervi and $L$. fabarum contained the same genes and the same genes were duplicated in each, implying duplication events occurred prior to the split from their most recent common ancestor. One of these duplicated genes appears to be duplicated again in $A$. ervi, or the L. fabarum copy has been lost.

\section{Chemosensory genes}

Genes underlying chemosensory reception play important roles in parasitoid mate and host localization [93, 94]. Several classes of chemosensory genes were annotated separately (Table 3). With these manual annotations, further studies can now be made with respect to life history characters including reproductive mode, specialization on aphid hosts, and mimicry.

\section{Chemosensory: soluble proteins (OBPs and CSPs)}

Odorant-binding proteins (OBPs) and chemosensory proteins (CSPs) are possible carriers of chemical molecules to sensory neurons. Hymenoptera have a wide range of known OBP genes, with up to 90 in N. vitripenis [95]. However, the numbers of these genes appear to be similar across parasitic wasps, with 14 in both species studied here and 15 recently described in D. alloeum [33]. Similarly, CSP numbers are in the same range within parasitic wasps (11 and 13 copies here, Table 3). Interestingly, two CSP sequences (one in A. ervi and one in $L$. fabarum) did not have the conserved cysteine motif, characteristic of this gene family. Further work should investigate if and how these genes function. 


\section{Chemosensory: odorant receptors (ORs)}

Odorant receptors (ORs) are known to detect volatile molecules. In total, we annotated 228 putative ORs in $A$. ervi and 156 in L. fabarum (Table 3). This is within the range of OR numbers annotated in other hymenopteran parasitoids, including: 79 in M. cingulum [96], 225 in $N$. vitripennis [97], and 187 in D. alloeum [33]. Interestingly, we annotated a larger set of ORs in $A$. ervi than in $L$. fabarum. One explanation is that $A$. ervi generally has more annotated genes than L. fabarum, and whatever broad pattern underlies the reduction in the gene repertoire of $L$. fabarum also affected OR genes. Another possibility is that the switch to an asexual reproduction has also led to a reduction in the number of OR genes, because pheromones linked to mate finding, recognition and courtship behavior are no longer necessary in an asexually reproducing species.

\section{Chemosensory: ionotropic chemosensory receptors (IRs)}

Ionotropic receptors (IRs) are involved in both odorant and gustatory molecule reception. In total, we annotated 38 putative IRs in A. ervi and 37 in L. fabarum (Table 3). Three putative co-receptors (IR 8a, IR 25a and IR 76b) were annotated in both species, one of which (IR 76b) was duplicated in A. ervi. This brings the total for the IR functional group to 42 and 40 genes for $A$. ervi and $L$. fabarum, respectively. This is within the range of IRs known from other parasitoid wasps such as Aphidius gifuensis (23 IRs identified in antennal transcriptome, Braconidae) [98], D. alloeum (51 IRs, Braconidae) [33] and N. vitripennis (47 IRs, Pteromalidae) [97]. A phylogenetic analysis of these genes showed a deeply rooted expansion in the IR genes (Supplementary Figure 29). Thus, in contrast to the expansion usually observed in hymenopteran ORs compared to other insect orders, IRs have not undergone major expansions in parasitic wasps, which is generally the case for a majority of insects with the exception of Blattodea [99].

\section{Sex determination}

The core sex determination genes (transformer, doublesex) are conserved in both species (Supplementary Table 17, Additional file 13). Notably, A. ervi possesses a putative transformer duplication. This scaffold carrying the duplication (scaffold2824) is only fragmentary, but a transformer duplicate has also been detected in the transcriptome of a member of the A. colemani species complex, suggesting a conserved presence within the genus [11]. In A. ervi, transformer appears to have an internal repeat of the CAM-domain, as is seen in the genus Asobara [100]. In contrast, there is no evidence of duplication in sex determination genes in L. fabarum. This supports the idea that complementary sex determination (CSD) in sexually reproducing L. fabarum populations is based on up-stream cues that differ from those known in other CSD species [101], whereas the CSD locus known from other hymenopterans is a paralog of transformer [102].

In addition to the core sex determination genes, we identified homologs of several genes related to sex determination (Supplementary Table 18). We identified fruitless in both genomes, which is associated with sexspecific behavior in taxa including Drosophila [103]. Both genomes also have homologs of sex-lethal which is the main determinant of sex in Drosophila [104], but not other insects. Drosophila has two homologs of this gene, and the single version in Hymenoptera may have more in common with the non-sex-lethal copy, called sister-ofsex-lethal. We identified homologs of the gene CWC22, including a duplication in $A$. ervi; this duplication is interesting because a duplicated copy of $C W C 22$ is the primary signal of sex determination in the house fly Musca domestica [105]. Lastly, there was a duplication of $R B P 1$ in both genomes. The duplication of RBP1 is not restricted to these species, nor is the duplication of $C W C 22$, which appears sporadically in Braconidae. Together, these annotations add to our growing knowledge of duplications of these genes and provide possibilities for further examinations of the role of duplications and specialization in association with sex determination.

\section{DNA methylation genes}

DNA methyltransferase genes are thought to be responsible for the generation and maintenance of DNA methylation. In general, DNA methyltransferase 3 (DNMT3) introduces de novo DNA methylation sites and DNA methyltransferase 1 (DNMT1) maintains and is essential for DNA methylation [106, 107]. A third gene, EEF1AKMT1 (formerly known as DNMT2), was once thought to act to methylate DNA but is now understood to methylate tRNA [107]. In both $A$. ervi and L. fabarum, we successfully identified homologs DNMT3 and EEF1AKMT1. In contrast, DNMT1 was not detected in either species (Table 4, Supplementary Table 19).

This adds to growing evidence that these genes are not conserved across Braconidae, as DNMT1 appears to be absent in several other braconid taxa, including

$\begin{aligned} & \text { Table } 4 \\
& \text { genes }\end{aligned}$
\begin{tabular}{llll} 
Species & Gene & Scaffold & e-value (Nasonia) \\
\hline A. ervi & EEF1AKMT1 homolog & scaffold94 & $1.00 \mathrm{E}-66$ \\
L. fabarum & & tig00000449 & $5.00 \mathrm{E}-63$ \\
A. ervi & DNA methyltransferase 3 & scaffold45 & $5.00 \mathrm{E}-138$ \\
L. fabarum & & tig00002022 & $9.00 \mathrm{E}-117$ \\
A. ervi & DNA methyltransferase 1 & no homolog detected \\
L. fabarum & & no homolog detected \\
\hline
\end{tabular}


Asobara tabida, A. japonica, and F. arisanus [108, 109]. However, DNMT1 is present in some braconids, including $M$. demolitor and Cotesia vestalis, and outside of Braconidae these genes are otherwise strongly conserved across insects [109]. In contrast, DNMT3, present here, is more often lost in insects [107].

This absence of DNMT1 helps to explain previous estimates of very low DNA methylation in $A$. ervi $(0.5 \%)$ [108]. We confirmed these low levels of methylation in $A$. ervi by mapping previously generated bisulfite sequencing data (Supplemental Figure 30) [108] to our genome assembly. We aligned $>80 \%$ of their data (total $94.5 \mathrm{Mbp}, 625,765 \mathrm{reads})$. The sequence coverage of this mapped data was low: only 63,554 methylation-available cytosines were covered and only 1216 were represented by two or more mapped reads. Nonetheless, of these mapped cytosines, the vast majority $(63,409)$ were never methylated, just 143 sites were always methylated, and two were variably methylated. Methylation-available cytosine classes were roughly equally distributed among three cytosine classes (CG: 0.154\%, CHG: $0.179 \%$, and $\mathrm{CHH}: 0.201 \%)$. This methylation rate is less than the 0.5\% estimated by Bewick et al. 2017 [108] and confirms a near absence of DNA methylation in A. ervi. Given the parallel absence of DNMT1 in L. fabarum, it seems likely that both species sequenced here may have very low levels of DNA methylation, and that this is not a significant mechanism in these species.

This stark reduction in DNA methylation is interesting, given that epigenetic mechanisms are likely important to insect defenses, including possible responses to host endosymbiont-dependent mechanisms [110-112]. As with the immune pathways discussed above, this could reflect a loss that is an adaptive response to developing within endosymbiont-protected hosts. It is also interesting that while one epigenetic mechanism seems to be absent in both $A$. ervi and L. fabarum, we see an increase in histone variants in L. fabarum (based on the OMA analysis of gene family expansion), and these histones could function in gene regulation. However, whether there is a functional or causal link between these two observations is yet to be tested.

\section{Discussion}

We have used two new, high quality genome assemblies to investigate the basis of infectivity and specificity in two parasitoid wasps that infect aphids. Within this, we have found more predicted genes in $A$. ervi than in $L$. fabarum (Tables 1 and 2). Comparisons with other parasitoids suggest that the lower number of predicted genes in $L$. fabarum is more likely due to their loss than to a gene gain in $A$. ervi. However, it is important to recognize that predictive annotation is imperfect and any missing genes should be specifically screened with more rigorous methods. Importantly, we found relatively high BUSCO scores in the predicted genes, suggesting that our gene prediction was largely successful and was not impacted by the low GC-content. One contribution to the overall difference in gene numbers could be in the larger number of orphan genes that were identified in $A$. ervi. The evolutionary origin of these orphan genes is not known [113, 114], but their retention or evolution could be important to understanding specific functions or traits in this taxon.

The two genomes contained different patterns of predicted TE content. The spread of reported TE coverage in arthropods is quite large, even among Drosophila species (ca. 2.7-25\%) [115], and variation in genome size has been broadly attributed to TE content $[35,116]$. The variation we observe here suggests that differences in predicted TE content may be evolutionary quite labile, even within closely related species with the same genome size. However, this could also be a consequence of the assembly methods, and this should be further studied.

\section{GC content}

The GC content of these two parasitoids is lower than any insect sequenced to date. This bias is accompanied by very strong codon bias (Fig. 2), which has functional consequences in terms of both expression efficiency and mRNA stability [117]. There is reason to expect that environment could contribute to the low GC content of these genomes; in taxa including bacteria [118] and plants [119] the environment has been shown to influence GC content via limitation in elements such as nitrogen. These two wasps parasitize aphids exclusively, and aphids themselves have relatively low genome-wide GC content, perhaps related to their high-sugar, lownitrogen, sap diet. This includes the pea aphid (Acyrthosiphon pisum, Additional file 6), which is a frequent host of $A$. ervi and also has notably low GC content (29.8\%) [120]. We did not observe a relationship in codon usage nor nitrogen content between wasps and other taxa in this system (i.e. aphids and their symbionts, Supplementary Figures 10-12). This suggests that the environment does not constrain these genomes in a way that drives lower GC content in these two parasitoids. However, it seems plausible that they were broadly limited by the environment, and that GC content was further constrained by other factors.

GC content in these two genomes could be low because of their relatively small size. Genome size and GC content are positively correlated in a diverse set of taxa including bacteria $[121,122]$, plants $[119,123]$, and vertebrates [124]. This widespread pattern may be driven by GC-rich repetitive elements that are more abundant in larger genomes, stronger selection on thermal stability 
in larger genomes, or thermal stability associated with the environment [119, 124]. Additionally, the apparent lack of DNA methylation in this system may contribute to low GC content (see below, and [108]). Methylation is a stabilizing factor with regard to GC content [125], so its absence could relax selection on GC content and allow it to decline. However, neither the absence of methylation nor codon bias are unique to these taxa, suggesting that some additional selective factors or genetic drift may have further shaped the composition of these two genomes.

Our finding that genes with adult-biased expression have lower GC content suggests that selection at different life-history stages may help shape genome content. Although the magnitude of these differences is not very large, subtle differences in gene content are hypothesized to be the result of selection in other systems [126]. It seems plausible that GC content differences among genes expressed at different life history stages could be selected in a process analogous to the small changes in gene expression that are linked to large phenotypic differences within and between species [127]. Lower GC content in adult-biased genes could be the consequence of differing energy demands and availability of resource across life stages. Expressing genes that best match their biased codon usage should be more efficient and accurate, resulting in lower energy consumption and faster turnover [128-131]. Expressing AT-rich genes is slightly more energy-efficient in itself, and this could favor otherwise neutral mutations from GC to AT [132]. There is good motivation for adults to have a greater demand for energy efficiency. Adult parasitoids usually feed on carbohydrate rich but protein and lipid poor resources like nectar, while performing costly tasks including flying, mating, and laying eggs. Meanwhile, parasitoid larvae are feeding on their aphid host's tissue, and likely benefit further from nutrients coming from the aphids' endosymbionts, while their only task is to grow as fast as possible [133-135].

Further explanations to be considered for low GC content include effective population size, translational efficiency, and mutational bias [131, 136, 137]. Although we do not have the power to test for GC-biased gene conversion with two taxa, the even lower third position GC content (A. ervi: $15.5 \%$ and L. fabarum: 10.7\%, Table 1) suggests that this should be tested in relation to other parasitoids [131]. Altogether, these patterns raise important questions about how codon biases impact genome content, and whether synonymous mutations are always functionally neutral $[73,138]$.

\section{Gene family expansions}

The most striking result of our gene family comparison was the expansion of F-box/LRR proteins in $A$. ervi relative to L. fabarum (232 vs. 68 genes across four orthologous groups, Supplementary Figure 16). The LRRs are a broad class of proteins associated with protein-protein interactions, including putative venom components in these parasitoids [24]. LRRs belong to a larger category of leucine rich repeat pattern recognition receptor proteins, which are an important component of innate immunity and cell-surface recognition of bacterial intruders and include Toll-like receptors in insects [139, 140]. While the functions of these proteins are diverse, expansion in F-box/LRR proteins has been shown to have specific function in immunity in parasitic insects. In the Hessian fly (Mayetiola destructor), fly-encoded Fbox/LRR proteins bind with plant-encoded proteins to form a complex that blocks the plant's immune defenses against the parasitic fly [141]. Thus, we hypothesize that the expansion of this class of proteins in both species is related to recognizing the diverse bacterial defenses of their broad aphid hosts. We argue that expansion of Fbox/LRR proteins in $A$. ervi relative to $L$. fabarum, may be associated with a recent arms race with respect to the immune defenses and protective endosymbionts of their host aphids.

Evidence for expansion of histone genes in L. fabarum may also have important functional consequence. All eukaryotic genomes examined to date contain multiple histone genes for the same histone variants found in humans (e.g. 22 genes for $\mathrm{H} 2 \mathrm{~B}$ or 16 genes for $\mathrm{H} 2 \mathrm{~A}$ in humans) [142], and it has recently been suggested that these histone variants are not functionally equivalent but rather play a role in chromatin regulation [142]. Hence, these variants could also play a role in several $L$. fabarum specific traits, including the switch from sexual to asexual reproduction (thelytoky); in mammals, sex determination has been linked to regulation via histone modification [143]. Alternatively, the expansion of histone genes could be related to their rapid development in hosts, as has been suggested for similar histone expansions in the parasitoid Diadromus collaris [32].

\section{Venom}

Venom injected at oviposition is crucial for successful reproduction in most parasitoid wasp species [23, 144]. Although these two species differ in their host range [40], comparison of venom proteins between species revealed that more than $50 \%$ of the proteins are shared between species (Fig. 4). Glutamyl transpeptidases are the most abundant proteins in the venom of both $A$. ervi and $L$. fabarum. Phylogenetic analysis suggests that they are the result of the duplication of a gene encoding a "classical" glutamyl transpeptidase prior to the separation of the two species (Fig. 5). These venom proteins have been suggested to be involved in the castration of the aphid host after parasitism [145]. LRR proteins, 
which were previously reported in the venom of $A$. ervi [24] and other Braconidae [146], are likely important for evading the hosts immune response.

\section{Key gene families}

We manually annotated more than 1000 genes (719 for A. ervi and 644 for L. fabarum, Table 3) from functional categories that are key to parasitoid life history and adaptation. This is especially important for large gene families, which are usually poorly annotated by automatic prediction [147]. Expansion and reductions in such gene families potentially underlie key adaptive differences between the two parasitoids, and necessitate accurate annotation.

\section{Desaturases}

Desaturases are an important gene family that introduce carbon-carbon double bonds in fatty acyl chains in insects [148, 149]. While these function broadly across taxa, a subset of these genes (specifically acyl-CoA desaturases) have been implicated in insect chemical recognition for roles including alkene production and modification of fatty acids [150]. This gene family is particularly interesting because it has been shown that Lysiphlebus cardui, a close relative of L. fabarum [38], have no unsaturated cuticular hydrocarbons ( $\mathrm{CHCs})$, just as is seen in its aphid host. This allows the parasitoid to go undetected in aphid colonies that are ant-tended and therefore better parasitize them [56]. We showed that the CHC profile of $L$. fabarum is also missing alkens and alkadiens (Supplementary Figure 21). In contrast, $A$. ervi produces a large amount of unsaturated hydrocarbons (Supplementary Figures 22 and 23). The loss of three annotated desaturase genes in L. fabarum compared to $A$. ervi might explain these differences in the composition of their $\mathrm{CHC}$ profiles, especially their apparent inability to synthesize dienes. Further work is needed to verify these losses in L. fabarum, identify the orthologs of the missing copies in $A$. ervi, and test if these potentially lost desaturase genes in L. fabarum are involved in the generation of unsaturated $\mathrm{CHCs}$ in $A$. ervi.

\section{Immune genes}

We found that some genes from the Imd and Toll pathways are absent from the genomes of $A$. ervi and $L$. fabarum, possibly including the gene imd, which has been present in other hymenopteran genomes analyzed to date. Strikingly, all of the genes in the Imd pathway, including those encoding GNBP- and PGRP, imd, $F A D D$, Dredd and Relish are missing in some aphid genomes (Acyrthosiphon pisum, Aphis gossypii and Diuaphis noxia) [151, 152], and imd is absent in the genomes of A. glycines, M. persicae, M. cerisae, and R. padi, some of which are hosts for A. ervi and L. fabarum [40]. The lack of an Imd pathway in aphids has been suggested to be an adaptation to tolerate the obligate bacterial symbiont, Buchnera aphidicola, as well as their facultative endosymbionts that are mostly gram-negative gammaproteobacteria (e.g. Hamiltonella defensa). Some of these facultative symbionts exhibit defensive activities against microbial pathogens and insect parasitoids [30, 153155 ] and may at least partially compensate for innate immune functions in aphids. A recent study has demonstrated the absence or incompleteness of the Imd pathway in some other Hemiptera species, suggesting repeated and independent losses of components of this pathway [156]. These authors also suggest that crosstalk could occur between the Imd and Toll pathways to target wider and overlapping arrays of microbes [156]. Whether similar cross-talk occurs in these two Aphidiidae (A. ervi and L. fabarum) warrants further study. Further work investigating this should formally verify their loss, as our lack of detection could be due to low homology or assembly errors.

Overall, our results suggest a possible convergent loss of some immunity genes, and possibly immune function, between these parasitoids and their aphid hosts. One reason could be that parasitoid larvae require basic nutrients during the early stages of development, which are supplied by the host and its symbionts, and thus an immune response from the parasitoid larvae might impair this function. Alternatively, but not exclusively, mounting an immune response against bacteria by the parasitoid larvae may be energetically costly and divert resources from its development. This idea of energy conservation would be especially relevant if the GC-reduction in these genomes is a consequence of energy conservation. It is still unclear whether other unrelated aphid parasitoids lack $i m d$, as well as the upstream activators and downstream effectors of the immune pathways. This altered immunity might lead to either a decrease in the wasps' responses to pathogenic bacteria, or they may use other defensive components to fight bacterial infections (perhaps some in common with aphids) that are yet to be discovered. For example, in $L$. fabarum recent transcriptomic work has shown that detoxifying genes may be a key component of parasitoid success [157], and these could play a role in immunity.

\section{Conclusions}

These two genomes have provided insight into adaptive evolution in parasitoids that infect aphids. Both genomes are extremely GC-poor, and the accompanying codon bias provides an excellent system for examining the chemical biases and selective forces that may overshadow molecular evolution in eukaryotes. We have also highlighted several groups of genes that are key to functional evolution across insects, including venom, sex 
determination, response to bacterial infection (F-box/ $L R R$ proteins), and near absence of DNA methylation. Moreover, the absence of certain immune genes (e.g. from the Imd and Toll pathways) in these two species is similar to losses in host aphids, and raises intriguing questions related to the effects of aphids' symbiosis on both aphid and parasitoid genomics. Lastly, differences between the two species including their OR gene repertoires and missing desaturase genes could help explain fundamental differences in their life history like the switch from sexual to asexual reproduction or aphid mimicry in L. fabarum.

Parasitoid wasps provide an excellent model for studying applied and basic biological questions, including host range (specialist vs generalist), reproductive mode (sexual vs asexual), antagonistic coevolution, genome evolution, and epigenetic regulation, to mention just a few. Our new genomic resources will open the way for future research, including work to understand mechanisms underlying host specialization, and adaptive changes associated with climate change [158, 159]. Lastly, the genomes of these two non-social Hymenoptera provide a valuable comparison for understanding processes specific to social insects with complex caste structure, and are a first but essential step to better understand the genetic architecture and evolution of traits that are important for a parasitic life style and their use in biological control.

\section{Methods}

*More complete methods are available in the Supplementary Material (Additional file 14).

\section{Insect collection and origin \\ Aphidius ervi}

Aphidius ervi samples used for whole-genome sequencing came from two different, sexually reproducing, isofemale lines established from parasitized aphids (recognizable as mummies) from fields of cereals and legumes in two different geographic zones in Chile: Region de Los Rios (S 39 51', W $73^{\circ} 7^{\prime}$ ) and Region del Maule (S 35 24', W $71^{\circ} 40^{\prime}$ ). Mummies (parasitized aphids) of Sitobion avenae aphids were sampled on wheat (Triticum aestivum L.) while mummies of Acyrthosiphon pisum aphids were sampled on Pisum sativum L. (pea aphid race). Aphid mummies were isolated in Petri dishes until adult parasitoids emerged. These two parasitoid lineages were separated in two cages with $H$. defensa-free hosts ad libitum and were propagated for approximately 75 generations under controlled conditions as described elsewhere [160, 161]. A further reduction of genetic variation was accomplished by establishing two isofemale $A$. ervi lines, which were maintained as described previously and propagated for approximately 10 generations before adult parasitoids (male and female) were collected live and stored in $1.5 \mathrm{ml}$ centrifuge tubes containing ethanol $(95 \%)$ at $-20^{\circ} \mathrm{C}$.

Aphidius ervi samples used for $\mathrm{CHC}$ analysis (below) were purchased from Katz Biotech AG (Baruth, Germany). Species identification was confirmed with COI barcoding following Hebert et al. [162]. Wasps sacrificed for $\mathrm{CHC}$ analysis were sampled from the first generation reared in the lab on Acyrthosiphon pisum strain LL01 [163], which were mass-reared on Vicia faba cv. Dreifach Weisse.

\section{Lysiphlebus fabarum}

Lysiphlebus fabarum samples used for whole-genome sequencing came from a single, asexually reproducing, isofemale line (IL07-64). This lineage was first collected in September 2007 from Wildberg, Zürich, Switzerland $\left(47^{\circ} 25^{\prime} 31^{\prime \prime} \mathrm{N} 8^{\circ} 49^{\prime} 00^{\prime \prime} \mathrm{E}\right)$ as mummies of the aphid Aphis fabae fabae, collected from the host plant Chenopodium album. In the lab, parasitoids were reared on $H$. defensafree $A$. $f$. fabae raised on broad bean plants (Vicia faba) under controlled conditions [16 h light: $8 \mathrm{~h}$ dark, $20^{\circ} \mathrm{C}$ ] until sampling in September 2013, or approximately 150 generations. Every lab generation was founded by ca. 10 individuals that were transferred to fresh host plants containing wasp-naïve aphids. Approximately 700 individuals were collected for whole-genome sequencing from a single generation in December 2013 and flash frozen at $-80^{\circ} \mathrm{C}$. To avoid sequencing non-wasp DNA, samples were sorted over dry ice to remove any contaminating host aphid or plant material.

For linkage group construction, separate L. fabarum collections were made from a sexually reproducing lineage. Here, we collected all sons produced by a single virgin female, sampled from the control lineage in a recently employed evolution experiment (Hamiltonella defensa-free lineage) [42]. Wasps were stored on ethanol until RAD-seq library construction. Lastly, a third population was sampled for the proteomic analysis of the venom-apparatus (below); these females came from the genetically-diverse starting population used to found the evolution experiment of Dennis et al. [42], and were sampled in December 2014.

\section{DNA extraction and library preparation Aphidius ervi}

DNA was extracted from adult haploid males of $A$. ervi in seven sub-samples (ca. 120 males each), reared on $S$. avenae. Total DNA was extracted using the DNEasy Plant Mini Kit (QIAGEN) following the manufacturer's instructions. DNA was quantified by spectrophotometry (Epoch Microplate Spectrophotometer, Biotek) and fluorometry (Qubit 3.0; Qubit DNA High sensitivity Assay Kit, Invitrogen), and quality was assessed using 1\% agarose gel electrophoresis. DNA samples were sent on 
dry ice to MACROGEN (Seoul, South Korea) and were used to produce Illumina paired-end (PE) and mate-pair (MP) libraries for sequencing. A PE library was constructed from one of the seven sub-samples (120 individuals, $1 \mu \mathrm{g}$ DNA) sheared by ultrasonication (Covaris) company, average sheared insert size: $350 \mathrm{bp})$. The remaining DNA samples were pooled (6 samples, 720 individuals) and used for MP sequencing ( $3 \mathrm{~kb}, 5 \mathrm{~kb}$ and 8 $\mathrm{kb}$ insert sizes), which were prepared with the Nextera mate-pair protocol (Illumina). All libraries were sequenced using an Illumina HiSeq 2000 sequencer (MACROGEN).

Long read PacBio (Pacific Biosciences) RS II sequencing was performed from a single DNA extraction of $270 \mathrm{~A}$. ervi females, reared on A. pisum. Genomic DNA was extracted using the Wizard genomic DNA purification kit (Promega) according to manufacturer instructions and quantified spectrophotometrically using a NanoDrop 2000 (Thermo Scientific). Input DNA was mechanically sheared to an average size distribution of $10 \mathrm{~Kb}$ (Covaris gTube, Kbiosciences) and the resulting library was size selected on a Blue Pippin Size Selection System (Cat \#BLU0001, Sage Science) to enrich fragments $>8 \mathrm{~Kb}$. Quality and quantity were checked on Bioanalyzer (Agilent Technologies) and Qubit, respectively. Four SMRT RSII cells with P6 chemistry were sequenced at GenoScreen, France.

\section{Lysiphlebus fabarum}

DNA was extracted from adult female L. fabarum in 10 sub-samples (50-100 wasps each) using the QIAmp DNA mini Kit (Qiagen) according to the manufacturer's instructions, with the inclusion of an overnight tissue digestion at $56^{\circ} \mathrm{C}$. Extracted DNA was then pooled and used to produce Illumina PE and MP, and PacBio libraries. The PE library was prepared using the Illumina Paired-End DNA protocol; the average fragment size was 180 base pairs (bp). The MP library (5 kb insert) was generated with the Nextera mate-pair protocol (Illumina). Both libraries were sequenced on the Illumina MiSeq in Paired-End mode at the Functional Genomics Center Zürich.

Long-read libraries for PacBio RS II sequencing were produced using the DNA Template Prep Kit 2.0 (Pacific Biosciences). Input DNA was mechanically sheared to an average size distribution of $10 \mathrm{~Kb}$ (Covaris gTube, Kbiosciences) and the resulting library was size selected on a Blue Pippin Size Selection System (Sage Science) machine to enrich fragments $>8 \mathrm{~Kb}$; quality and quantity were checked on the Bioanalyzer and Qubit, respectively. Ten SMRT Cells were sequenced at the Functional Genomics Center Zürich.

\section{Genome assembly}

\section{Aphidius ervi}

Library quality was checked with FastQC ver. 0.11.3

[164]. Paired-end libraries were processed with
Trimmomatic ver. 0.35 [165] for trimming Illumina adapters/primers, low quality bases $(\mathrm{Q}<25,4 \mathrm{bp}$ window) and discarding sequences shorter than $50 \mathrm{bp}$ or without its mate-pair. In the case of Mate-Pair libraries, removal of improperly oriented read-pairs and removal of Nextera adapters was performed using NextClip [166]. Filtered PE and MP libraries were used for genome assembly with Platanus ver. 1.2.1 with default parameters [167], gap closing was performed with GapCloser [168]. Scaffolding with PacBio reads was performed using a modified version of SSPACE-LR v1.1 [169], with the maximum link option set by -a 250. Finally, the gaps of this last version were filled with the Illumina reads using GapCloser.

\section{Lysiphlebus fabarum}

Library quality was also checked with FastQC [164]. Illumina reads were filtered using Trimmomatic ver 0.33 to remove low quality sequences $(\mathrm{Q}<25,4 \mathrm{bp}$ window), to trim all Illumina primers, and to discard any sequence shorter than $50 \mathrm{bp}$ or without its mate-pair. NextClip was used to remove all improperly oriented read pairs.

Raw PacBio reads were error-corrected using the quality filtered Illumina data with the program Proovread [170]. These error-corrected reads were then used for de novo assembly in the program canu v1.0 [171]. Since our PacBio reads were expected to have approximately $30 \mathrm{X}$ coverage (based on the presumed size of $128 \mathrm{Mbp}$ ), canu was run with the recommended settings for low coverage data (corMhapSensitivity $=$ high corMinCoverage $=2$ errorRate $=0.035$ ), and with the specification that the genome is approximately $128 \mathrm{Mbp}$. The resulting assembly was polished using a single iteration of Pilon [172] to correct for both single nucleotide and small indel errors, using mapping of both the MP and PE data, generated with bwa-mem [173].

\section{Linkage map construction in L. fabarum}

For linkage map construction, we followed the methodology described in Wang et al. [174] and Purcell et al. [175]. In brief, we genotyped 124 haploid male offspring from one sexual female using ddRADseq. Whole-body DNA was high-salt extracted [176], digested with the EcoRI and MseI restriction enzymes, and ligated with individual barcodes [177, 178]. Barcoded samples were purified and amplified with Illumina indexed primers by PCR [178] and quality-checked on an agarose gel.

Pooled samples were sequenced on the Illumina HiSeq2500. Raw single-end libraries were quality filtered and de-multiplexed using the process_radtags routine within Stacks v1.28 with default parameters [179], and further filtered for possible adapter contamination using custom scripts. Genotyping was performed by mapping all samples against the $L$. fabarum draft genome 
assembly using bowtie2 [180] with rg-id, sensitive and end-to-end options. Genotypes were extracted using samtools mpileup [181] and bcftools (haploid option) [182]. We filtered the resulting genotypes for a quality score $>20$ and removed loci with $>20 \%$ missing data and/or a minor allele frequency $<15 \%$ using VCFtools v0.1.12b [183]. After filtering, 1319 biallelic SNPs in 90 offspring remained.

For constructing linkage groups, we followed Gadau 2009 [184] to account for the unknown phase of the maternal genotype. In short, we duplicated the haploid male genotypes and reversed the phase for one duplicated set and removed one of the mirror linkage group sets after mapping. We generated the map using MSTmap [185] on the data with following parameters: population_type DH, distance_function kosambi, no_map_dist 15.0, no_ map_size 2, missing_threshold 1.00 , and the cut_off_p_ value $1 \mathrm{e}-6$. The cut-off $p$-value was adjusted to create a linkage map of five linkage groups, however the biggest group had a gap of $>70 \mathrm{cM}$, indicating a false fusion of two groups, which we split in two groups. This result corresponded to the six chromosomes previously described for L. fabarum [52], these were visualized with AllMaps [186]. Initial mapping showed that 14 SNPs at one end of tig0000000 mapped to Chromosome1, while the majority of the contig (>150,000 bp) mapped to Chromosome 2. Thus, these SNPs were removed from the linkage maps, and it is advised that subsequent drafts of the L. fabarum genome should split this contig around position 153,900 .

\section{Genome completeness and synteny}

Completeness of the two assemblies was assessed by identifying Benchmarking Universal Single-Copy Orthologs (BUSCOs) using the BUSCO v3.0.2 pipeline in genome mode [187]. We identified single copy orthologs based on the insecta_db9 (1066 genes, training species: Nasonia vitripennis).

Synteny between the two genomes was assessed using the NUCmer aligner, which is part of the MUMmer v3.23 package [66]. For this, we used the L. fabarum chromosomes as the reference, and included the scaffolds not incorporated into chromosomes (total 1407 pieces). The $A$. ervi assembly was mapped to this using the default settings of NUCmer.

\section{Predictive gene annotation}

For both assembled genomes, gene predictions were generated using MAKER2 [188]. Within MAKER2, predictive training was performed in a three step process. A first set of genes was predicted by similarity to known proteins or contigs from RNAseq in the same species (described below). This gene set was used thereafter for training both Augustus [189] and SNAP [190], in two steps, with the results of the first training re-used to train the software in the second round. Transcriptomic evidence was provided separately for each species. For $A$. ervi, six separate de novo transcriptome assemblies from Trinity [191] were constructed, one each for the adults reared on different hosts (NCBI PRJNA377544) [160]. For each transcript, we only included variants based on filtering with RSEM v 1.2.21 using the option -fpkm_cutoff 1.0, --isopct_cutoff $=15.00$. This resulted in 452,783 transcripts. For $L$. fabarum, we utilized a joint transcriptome, built using RNAseq data (NCBI PRJNA290156) collected from adults [42] and 4-5 day old larvae [157]. Peptide evidence came from the Hymenoptera genomes database (http://hymenopteragenome.org, Acromyrmex echiniator v3.8, Apis mellifera v3.2, Nasonia vitripennis v1.2), from the BioInformatics Platform of Agroecosystems Arthropod database (https://bipaa.genouest.org, Hyposoter didymator v1.0), and Drosophila melanogaster (http://flybase.org, v6.13), and SwissProt (October 2016) databases. Summary statistics were generated with GAG [192]. Transcriptomic support for the predicted genes was estimated by mapping available transcriptomic data (same as above) to the respective genomes using STAR [193] in the "quantMode".

\section{Contamination filtering}

We screened for contamination in two steps. First, we used blobtools [64] to examine scaffolds based on sequencing coverage (from the paired-end reads mapped with bwa-mem), GC content, and top BLAST hit (cutoff 1e-25). We further screened the predicted genes to assign them to either host aphid (Acyrthosiphon pisum and Aphis glycines) or to the other parasitoid. Scaffolds that did not match to Arthropoda, and predicted genes that matched to aphid were manually examined. In both cases, we retained genes and regions with no known match, as these warrant future investigation.

\section{Functional annotation}

The putative functions of the proteins predicted by the above pipeline were identified based on BLASTp (v2.5.0) matches against Genbank $n r$ (non-redundant GenBank CDS translations+PDB + SwissProt+PIR + PRF) release $12 / 2016$ and interproscan v5 against Interpro (1.21.2017). GO terms associations were collected from BLAST $n r$ and interproscan results with blast2GO (v2.2). Finally, transmembrane domains were identified with Hidden Markov Models (HMM) in tmhmm v2.0c, and peptide signals with signal (euk v4.1) [194, 195].

\section{Transposable elements}

Transposable elements (TE) were predicted using the REPET pipeline [196], combining de novo and homology-based annotations. Repetitive elements were identified de novo across all scaffolds larger than the 
scaffold N50 for each species, following recommendations from the developers of REPET for draft genome assemblies. Within these, repetitive elements were identified using a BLAST-based alignment of each genome to itself followed by clustering with Recon [197], Grouper [198] and Piler [199]. For each cluster, a consensus sequence was generated by multiple alignment of all clustered elements with MAP [200]. The resulting consensus was then scanned for conserved structural features or homology to nucleotide and amino acid sequences from known TEs (RepBase 20.05) [201, 202] using BLASTER (tblastx, blastx) [196] or HMM profiles of repetitive elements (Pfam database 27.0) using hmmer3 [203]. Based on identified features, repeats were classified using Wicker's TE classification as implemented in the PASTEclassifier [204]. The resulting de novo TE library for the genome was then filtered to retain only the elements with at least one perfect match in the genome. Subsequently, all TEs in the full genomes were annotated with REPET's TE annotation pipeline. Reference TE sequences were aligned to the genome using BLASTER, Repeat Masker [205] and CENSOR [206]. The resulting HSPs were filtered using an empirical statistical filter implemented in REPET [196] and combined using MATCHER [198]. Short repeats were identified using TRF [207] and Mreps [208]. Elements in genomic sequences with homology with known repbase elements (RepBase 20.05) were identified with BLASTER (BLASTx, tBLASTx) and curated by MATCHER. Finally, redundant TEs and spurious SSR annotations were filtered and separate annotations for the same TE locus were combined using REPET's "long join procedure". DNApipeTE [209] was run to estimate repeat content from unassembled raw reads. For this, we first sampled $1,000,000$ paired-end reads (100 bp) from each species and filtered these for adapter contamination with Trimmomatic 0.39. DNApipeTE was run with "-sample_number 3", "-genome_coverage 0.5 "against the arthropodspecific RepeatMasker library.

\section{GC content and codon usage}

We examined several measures of nucleotide composition, at both the nucleotide and protein level. Whole genome GC content was calculated by totaling the numbers of A, C, T, and G in the entire assembly. In the predicted coding sequences, this was also calculated separately for each predicted gene and third position GC composition was calculated separately in the predicted coding sequences. In all cases, this was done with the sscu package in R [210]. Relative Synonymous Codon Usage (RSCU) was extracted from the entire CDS using the seqin $R$ package in $R$ [211], and visualized with a PCA (R packages factoextra, reshape, and ggplot2) [212214]. To examine GC content in coding genes of other insects, we downloaded the 118 available CDS in the RefSeq database of NCBI (date: October 2018) and again calculated per-gene GC content.

To examine the GC content of life-stage biased transcripts, we compared GC content in the genes that were significantly differentially expressed between adults and larvae, and in the most highly expressed genes in this data. We utilized previously generated transcriptomes from 43 pools of adult females [42] and 24 individual larval [157] L. fabarum. Differential expression was calculated using DESeq2 [215], and genes with an FDR < 0.05 were deemed significantly differentially expressed. The full models of expression accounted for aphid host and replicate; the full analysis pipeline is detailed in the Supplemental Materials. GC content between these pools of genes was compared with a two-sided t-test, implemented in $\mathrm{R}$.

\section{Orphan genes}

We identified orphan genes as those for which we could not find orthologs in any other sequenced genomes (Supplementary Table 11). To do this, we first used OrthoFinder [216] to generate clusters of orthologous and paralogous genes among the predicted genes (CDS) from the genomes of $A$. ervi and L. fabarum, as well as five other sequenced parasitoids (Diachasma alloeum, Fopius arisanus, Macrocentrus cingulum, Microplitis demolitor and Nasonia vitripennis). OrthoFinder produces a set of genes that were not assigned to any orthogroup. We identified species specific genes, which we are calling orphan genes, by removing all genes that had hits to any other genes in the $n t, n r$, and swissprot NCBI database (June 2019). Within these putative orphans, we only retained those with transcriptomic support.

\section{Gene family expansions}

We examined gene families that have expanded and contracted in A. ervi and L. fabarum relative to one another using the OMA standalone package (v2.2.0, default values) [74]. OMA was used to compute orthologs (OMA groups) and Hierarchical Orthologous Groups (HOGs) for the predicted proteins of L. fabarum (OGS1) and A. ervi (OGS3): 15,203 and 20,344, respectively. While OMA groups consist of strict 1:1 orthologs between OGS1 and OGS3, HOGs contain all orthologs and paralogs of a given predicted gene family. HOGs were parsed with a custom Perl script to identify all gene families in which one of the wasp species contained more members than the other. We focused on only the groups that contained more than 20 genes (10 groups, Supplementary Figure 15). These were identified by BLASTx against the $n r$ database in NCBI. 


\section{Venom proteins}

The $L$. fabarum venom proteomic analysis was performed from 10 extracted venom glands (Supplementary Figure 17). The 16 most visible bands in 1D gel electrophoresis were cut, digested with trypsin and analyzed by mass spectrometry. All raw data files generated by mass spectrometry were processed to generate mgf files and searched against: (i) the L. fabarum proteome predicted from the genome ( $L$. fabarum annotation v1.0 proteins) and (ii) the L. fabarum de novo transcriptome [42] using the MASCOT software v2.3 [217]. The mass spectrometry proteomics data are deposited in the ProteomeXchange Consortium (proteomecentral.proteomexchange. org) via the PRIDE partner repository [62], with the ID PXD015758.

Sequence annotation was performed based on BLAST similarity searches. Signal peptide prediction was performed with SignalP [194, 195]. Searches for protein domains was performed with PfamScan [218] and venom protein genes were identified using the BLAST tools in Apollo [79, 81]. Multiple amino acid sequence alignments were made with MUSCLE [219, 220]. Phylogenetic analysis was performed using maximum likelihood (ML) with PhyML 3.0 [221]. SMS was used to select the best-fit model of amino acid substitution for ML phylogeny [222].

\section{Manual gene curation}

The two genome assemblies were manually curated for a number of gene families of interest. This improved their structural and functional annotation for more in-depth analysis. Manual curation, performed in Apollo included the inspection of stop/start codons, duplications (both true and erroneous), transcriptomic support, and concordance with the predicted gene models.

\section{Desaturases}

Desaturase genes in both genomes were automatically identified and annotated with GeMoMa [223] using desaturase gene annotations from Diachasma alloeum, Fopius arisanus, and Microplitis demolitor, retrieved from NCBI's protein database as queries (retrieved May 2017). Additionally, all desaturase genes were manually inspected.

To determine the cuticular hydrocarbon $(\mathrm{CHC})$ profiles in A. ervi, wasps were freeze-killed and stored separately by sex at $-20^{\circ} \mathrm{C}$. For $\mathrm{CHC}$ extraction, single individuals were covered with $50 \mu \mathrm{l}$ of MS pure hexane (UniSolv) in $2 \mathrm{ml} \mathrm{GC}$ vials (Agilent Technologies,) and swirled for $10 \mathrm{~min}$ on a Thermo-shaker (IKA KS 130 Basic, Staufen). The hexane extracts where then transferred to a fresh conical $250 \mu \mathrm{l} \mathrm{GC}$ insert (Agilent Technologies), where the hexane was completely evaporated under a constant flow of $\mathrm{CO}_{2}$. The dried extract was then resuspended in $5 \mu \mathrm{l}$ of a hexane solution containing $7.5 \mathrm{ng} / \mu \mathrm{l}$ of $\mathrm{n}$-dodecane (EMD Millipore Corp.) as an internal standard. Three microlitre of the extract were then injected into a GC-QQQ Triple Quad (GC: 7890B, Triple Quad: 7010B, Agilent) with a PAL Autosampler system operating in electron impact ionization mode. The split/splitless injector was operated at $300^{\circ} \mathrm{C}$ in Pulsed splitless mode at 20 psi until 0.75 min with the Purge Flow to Split Vent set at $50 \mathrm{~mL} / \mathrm{min}$ at $0.9 \mathrm{~min}$. Separation of compounds was performed on a $30 \mathrm{~m} \times$ $0.25 \mathrm{~mm}$ ID $\times 0.25 \mu \mathrm{m} \quad$ HP-1 Dimethylpolysiloxane column (Agilent) with a temperature program starting from $60^{\circ} \mathrm{C}$, held for $2 \mathrm{~min}$, and increasing by $50^{\circ} \mathrm{C}$ per min to $200^{\circ} \mathrm{C}$, held for $1 \mathrm{~min}$, followed by an increase of $8{ }^{\circ} \mathrm{C}$ per min to $250^{\circ} \mathrm{C}$, held again for $1 \mathrm{~min}$, and finally $4{ }^{\circ} \mathrm{C}$ per min to $320^{\circ} \mathrm{C}$, held for $10 \mathrm{~min}$. Post Run was set to $325^{\circ} \mathrm{C}$ for $5 \mathrm{~min}$. Helium served as carrier gas with a constant flow of $1.2 \mathrm{ml}$ per min and a pressure of 10.42 psi. Initially $\mathrm{CHC}$ peaks were identified and the chromatogram was generated using the Qualitative Analysis Navigator of the MassHunter Workstation Software (vB.08.00 / Build 8.0.8208.0, Agilent). CHC quantification was performed using the Quantitative Analysis MassHunter Workstation Software (vB.09.00 / Build 9.0.647.0, Agilent). Peaks were quantified using their diagnostic (or the neighboring most abundant) ion as quantifier and several characteristic ions in their mass spectra as qualifiers to allow for unambiguous detection by the quantification software. The pre-defined integrator Agile 2 was used for the peak integration algorithm to allow for maximum flexibility. All peaks were then additionally checked for correct integration and quantification, and, where necessary, re-integrated manually. Percentages were based on the respective averages of four individual female $\mathrm{CHC}$ extracts.

\section{Immune genes}

The list of immune genes to be searched against the $A$. ervi and $L$. fabarum genomes was established based on Drosophila melanogaster lists from the Lemaitre laboratory (lemaitrelab.epfl.ch/fr/ressources) [224, 225] and from the interactive fly web site [84] (www.sdbonline. org/sites/fly/aignfam/immune.htm). Each D. melanogaster protein sequence was used in BLAST similarity searches against the two predicted wasp proteomes (BLASTp) and against the entire assembly (tBLASTn) when no direct match was obtained. The best match was retained, and its protein sequence was used to perform a new BLAST search using the NCBI non-redundant protein sequence database to confirm the similarity with the D. melanogaster sequence. When both results were concordant, the retained sequence was then searched for in Nasonia vitripennis and Apis mellifera proteomes to identify homologous genes in these species. 


\section{Osiris genes}

Osiris gene orthologs were determined with a two-part approach: candidate gene categorization followed by phylogenetic clustering. Candidate Osiris genes were generated using HMM with hmmer v3.1b2 [226] and local alignment searching [227]. A custom HMM was derived using all 24 well annotated and curated Osiris genes of Drosophila melanogaster. Next, an HMM search was performed on the $A$. ervi and L. fabarum proteomes, extracting all protein models with $P<0.05$. Similarly, all D. melanogaster Osiris orthologs were searched in the annotated proteomes of $A$. ervi and $L$. fabarum using protein BLAST $(\mathrm{e}<0.05)$. The top BLAST hit for each ortholog was then searched within each parasitoid genome for additional paralogs $(\mathrm{e}<$ $0.001)$. All unique candidates from the above approaches were then aligned using MAFFT [228], and an approximate maximum-likelihood phylogeny was constructed using FastTree [229] via the CIPRES science gateway of Xsede [230]. The species used were: the fruit fly (D. melanogaster), the tobacco hornworm moth (Manduca sexta), the silkworm moth (Bombyx mori), the flour beetle (Tribolium castaneum), the jewel wasp (Nasonia vitripennis), the honeybee (Apis mellifera), the buff tail bumble bee (Bombus terrestris), the red harvester ant ( Pogonomyrmex barbatus), the Florida carpenter ant (Camponotus floridanus), and Jerdon's jumping ant (Harpegnathos saltator).

\section{OXPHOS}

Genes involved in the oxidative phosphorylation pathway (OXPHOS) were identified in several steps. Initial matches were obtained using the nuclear-encoded OXPHOS proteins from Nasonia vitripennis [231]; J. D. Gibson unpublished] and Drosophila melanogaster (downloaded from www.mitocomp.uniba.it) [232]. These two protein sets were used as queries to search the protein models predicted for A. ervi and L. fabarum (blastp) [233]. Here, preference was given to matches to $N$. vitripennis. Next, genes from the $N$. vitripennis and $D$. melanogaster reference set that did not have a match in the predicted proteins were used as queries to search the genome-assembly (BLASTn), in case they were not in the predicted gene models. Gene models for all matches were then built up manually, based on concurrent evidence from the matches in both $A$. ervi and L. fabarum and their available expression evidence. The resulting protein models were aligned to one another and to $N$. vitripennis using MAFFT [228] to identify missing or extraneous sections. These results were used as queries to search the $N$. vitripennis proteins to ensure that all matches are reciprocal-best-BLAST-hits. Gene naming was assigned based on the existing $N$. vitripennis nomenclature. Potential duplicates were flagged based on BLAST-matches back to $N$. vitripennis (Additional file 12).

\section{Olfactory genes \\ Odorant-binding proteins (OBPs) and chemosensory proteins (CSPs)}

To identify OBPs based on homology to known sequences, we retrieved $60 \mathrm{OBP}$ amino acid sequences from other Braconidae (namely Fopius arisanus bw Microplitis demolitor) from GenBank. To this, we added seven OBPs found in a previous transcriptome of $A$. ervi (Patrizia Falabella, unpublished, EBI SRI Accessions: ERS3933807- ERS3933809). To identify CSPs, we used CSP amino acid sequences from more Hymenoptera species (Apis mellifera, Nasonia vitripennis, Fopius arisanus and Microplitis demolitor). These sets were used as query against $A$. ervi and $L$. fabarum genomes using tBLASTn (e-value cutoff 10e-3 for OBPs and 10e-2 for CSPs). Genomic scaffolds that presented a hit with at least one of the query sequences were selected. To identify precise intron/exon boundaries, the Braconidae OBP and CSP amino acid sequences were then aligned on these scaffolds with Scipio [234] and Exonerate [235]. These alignments were used to generate gene models in Apollo. Gene models were manually curated based on homology with other Hymenoptera OBP and CSP genes and on RNAseq data, when available. Lastly, the deduced amino acid sequences of $A$. ervi and $L$. fabarum OBP and CSP candidates were then used as query for another tBLASTn search against the genomes in an iterative process to identify any additional OBPs. Since both OBPs and CSPs are secreted proteins, the occurrence of a signal peptide was verified using SignalP [194, 195].

\section{Odorant receptors (ORs)}

ORs were annotated using available OR gene models from Diachasma alloeum, Fopius arisanus, and Microplitis demolitor retrieved from NCBIs protein database (retrieved May 2017). Preliminary OR genes models for A. ervi and L. fabarum were predicted with exonerate (v2.4.0), GeMoMa v1.4 [223], and combined with EVidence Modeler v1.1.1 [236]. These preliminary models were subsequently screened for the 7 tm_6 protein domain (with PfamScan v1.5) and manually curated in WebApollo2.

In an iterative approach, we annotated the IRs using known IR sequences from Apis melifera, Drosophila melanogaster, Microplitis demolitor and Nasonia vitripennis as queries to identify IRs in the genomes of $A$. ervi and L. fabarum. The hymenopteran IR sequences served as input for the prediction of initial gene model with Exonerate [235] and GeMoMa [223]. Then, we inspected and edited homologous gene models from each tool in the Apollo genome browser to adjust for proper splice sites, 
start and stop codons in agreement with spliced RNASeq reads. After a first round of prediction, we repeated the whole process and provided the amino acid sequences of curated IR genes as queries for another round of predictions to identify any remaining paralogous IRs.

Multiple sequence alignments of the IRs were computed with hmmalign [237] using a custom IR HMM to guide the alignments [99]. Gene trees were generated with FastTree v2 [238] using the pseudocount option and further parameters for the reconstruction of an exhaustive, accurate tree (options: -pseudo -spr 4 -mlacc 2 -slownni). Resulting trees were visualized with iTOL v4 [239], well supported IR clusters and expansions were highlighted by color (branch support $>0.9$ ).

\section{Sex determination genes}

Ortholog searches were performed with tBLASTn [233] against the genomic scaffolds. Hits with an e-value smaller than 1e-20 were assessed, apart from transformer and doublesex where any hit was surveyed. Doublesex, Transformer-2 and Transformer peptide sequences of Asobara tabida (NCBI accessions MF074326-MF074334) were used as queries for the core sex determination genes. This braconid species is the closest relative whose sex determination mechanism has been examined (Geuverink et al., 2018). The putative transformer B sequence of $A$. ervi was blasted for verification against the transcriptome of Aphidius colemani [11] and a highly conserved fragment was detected (GBVE01021531). Peptide sequences of sex determination related genes to use as queries were taken from Nasonia vitripennis: Fruitless (NP_001157594), SexLethal homolog (XP_016836645), pre-mRNA-splicing factor CWC22 homolog (XP_001601117) and RNA-binding protein 1-like (XP_008202465). Hidden Markov models were not used as gene models because the ensuing peptide predictions did not contain all putative homologs (e.g. transformerB in A. ervi) due to fragmentation of the scaffolds containing the candidate genes.

\section{DNA methylation genes}

The genomes were searched with tBLASTn [233] for the presence of potential DNA methyltransferase genes using peptide sequences from Apis mellifera and N. vitripennis as queries. These species differ in their copy number of DNMT1, with two copies (NP_001164522, XP_ 006562865) in the honeybee A. mellifera [240] and three copies (NP_001164521,XP_008217946, XP_001607336) in the wasp $N$. vitripennis [37]. To assess presence of DNMT1 copies in other braconids, tBLASTn searches with DNMT1 queries were performed on whole genome shotgun assemblies of $M$. demolitor, $F$. arisanus and $C$. vestalis $[32,34,36]$ al. 2019). DNMT2, currently characterized as EEF1AKMT1 (EEF1A Lysine Methyltransferase
1), has become redundant in the list of DNA methyltransferase genes as it methylates tRNA instead, but was surveyed here as a positive control ( $N$. vitripennis NP_ 001123319, A. mellifera XP_003251471). DNMT3 peptide sequences from $N$. vitripennis (XP_001599223) and from A. mellifera (NP_001177350) were used as queries for this gene. Low levels of methylation were confirmed by mapping the whole genome bisulfite sequencing data generated by Bewick et al. [108] back to the A. ervi genome assembly.

\section{Supplementary information}

Supplementary information accompanies this paper at https://doi.org/10 1186/s12864-020-6764-0.

Additional file 1. Contamination filtering for $A$. ervi. Details of both blast-based and blobtools contamination filtering performed on the $A$. ervi genome.

Additional file 2. Contamination filtering for $L$. fabarum. Details of both blast-based and blobtools contamination filtering performed on the $L$. fabarum genome.

Additional file 3. Linkage groups in L. fabarum. Details of scaffold positions used to construct linkage groups for $L$. fabarum.

Additional file 4. Orphan genes in A. ervi. Fasta file containing the 2568 orphan genes identified in the A. ervi assembly.

Additional file 5. Orphan genes in L. fabarum. Fasta file containing the 968 orphan genes identified in the L. fabarum assembly.

Additional file 6. Details of CDS used to compare GC content across taxa. Genbank numbers and taxonomic information for genome (CDS) graphed in Supplementary Figure 9, detailing the GC content in predicted genes of other arthropods.

Additional file 7. Analysis of GC content and expression. Full details of analyses that drew from expression data in both taxa. This file details (a) GC content, carbon, and nitrogen for all predicted genes, (b) the most highly expressed genes in both taxa and (c) full analysis of differential expression between adult and larval L. fabarum, and corresponding comparison of GC content.

Additional file 8. Ortholog MAtrix (OMA) results. Summary of all Hierarchical Ortholog Groups (HOGs) predicted by OMA, including details of $L R R$ genes.

Additional file 9. Venom gene annotations. Annotation details of venom genes in L. fabarum and A. ervi.

Additional file 10. Immune gene annotations. Details of immune gene annotation in L. fabarum and A. ervi.

Additional file 11. Expression of Osiris genes. Expression details of Osiris genes in L. fabarum and A. ervi, including comparison of expression between larval and adult L. fabarum.

Additional file 12. OXPHOS gene annotations. Details of annotated OXPHOS genes, including duplications in the assembly.

Additional file 13. Annotation of sex determination genes. Details of sex determination gene annotations.

Additional file 14. Supplementary Materials.

\section{Abbreviations}

A, T, C, G, and U: Adenine, Thymine, Cytosine, Guanine, and Uracile, nucleotides; bp: Base Pair; BIPAA: Biolnformatics Platform for Agroecosystem Arthropods (bipaa.genouest.org); BLAST: Basic Local Alignment Search Tool; BUSCO: Benchmarking Universal Single-Copy Orthologs; CDS: Predicted Coding Sequence; CSD: Complementary Sex Determination; CHC: Cuticular Hydrocarbons; DNMT: DNA Methyltransferase genes; CSP: Chemosensory Protein; GO: Gene Ontology; HMM: Hidden Markov Model; HOG: Hierarchical Ortholog Group; IR: Ionotropic Receptor; LRR: Leucine Rich Repeat Proteins; 
Mbp: Mega Base Pairs, or 1000,000 bp; MP: Mate-pair sequence data; NCBI: National Center for Biotechnology Information; N50: A measure of genome completeness. The length of the scaffold containing the middle nucleotide; OBP: Odorant-binding Protein; OR: Odorant Receptor; OXPHOS: Oxidative Phosphorylation; PE: Paired-end sequence data; RSCU: Relative Synonymous Codon Usage; TE: Transposable Element

\section{Acknowledgements}

Thanks to the many people who helped with collections and insect rearing, especially Paula Rodriguez (EAWAG), Laury Arthaud and Christian Rebuf (ESIM, INRAE-ISA), Francisca Zepeda-Paulo (UACH), Sebastian Ortiz-Martinez, Cinthya Villegas, and Daniela Sepúlveda (UTALCA). Lucia Briones (UTALCA) and Dominique Cazes (ESIM, INRAE-ISA) provided help in with A. ervi DNA extractions. Paul Saffert (Uni Potsdam) provided valuable discussion leading to the codon usage analysis. David Pratella (ESIM, INRAE-ISA) provided help on the annotation of immune genes.

Lysiphlebus fabarum data were generated in collaboration with the Genetic Diversity Centre (GDC, with particular thanks to Stefan Zoller and JeanClaude Walser), the FGCZ at ETH Zurich, and utilized the ETH Scientific Computing Cluster (Euler). Orthologs were computed on the University of Potsdam's High Performance Computing Cluster Orson2, managed by the ZIM. The ESIM team is supported by the French Government (National Research Agency, ANR) through the "Investments for the Future" LABEX SIGNALIFE: program reference \# ANR-11-LABX-0028-01. Mark Lammers would like to thank Panagiotis Provataris (ZFMK, Bonn, Germany) for bringing to our attention the existent small whole genome bisulfite sequencing data set for Aphidius ervi.

DNA sequences from the Myzus genomes used in comparative analysis of codon usage were downloaded from AphidBase. Funding for Myzus persicae clone G006 genomic sequencing was provided by USDA-NIFA award 201065105-20558. Funding for M. persicae clone O genomic sequencing was provided by The Genome Analyses Centre (TGAC) Capacity and Capability Challenge program (project CCC-15 and BB/J004553/1), from the Biotechnology and Biological Sciences Research Council (BBSRC), and the John Innes Foundation.

\section{Authors' contributions}

$A B D, G I B, C F, B I L, D T, J-C S, C V$, FL, and JG conceived of the study, participated in analyses. ABD performed GC-content and gene expression analyses. SR, $A B D, A B$, and $F L$ performed de novo assemblies, predictive annotation, and associated bioinformatic analyses. ABD and GIB reared insects and performed molecular work. LS and ME analyzed TE content. JB1, ZD, and TS conducted sequencing and analysis to construct linkage maps. ABD, GIB, LS, LB, JB2, JG, JDG, EC, PF, DC, J-LG, EG, EJ-J, IL, LM-G, CM, NM, NP, MP, RS, CS, ST, HV, contributed to gene family annotation and analysis. ABD and SH performed synteny and gene family expansion analyses. GIB identified orphan genes. ML analyzed methylation patterns. JB3 and $\mathrm{CH}$ performed analysis of $\mathrm{CHC}$ profiles. MB, DC, and J-LG performed venom analysis. All authors read and contributed to preparation of the final manuscript.

\section{Funding}

Aphidius ervi sequencing was funded by FONDECYT grants 1130483 and 1170943, and Iniciativa Científica Milenio (ICM) NC120027 (both to Christian Figueroa and Blas Lavandero, Universidad de Talca, Chile), INRAE (AIP "séquençage" INRA Rennes, France), and funding from ESIM team (Marylène Poirié, INRAE-ISA Sophia Antipolis, France) and BGI (funding to Denis Tagu, INRAE Rennes, France).

Lysiphlebus fabarum sequencing was funded by an SNSF professorship to Christoph Vorburger (grant nrs. PP00P3_123376 and PP00P3_146341). TS acknowledges SNSF grant nr PP00P3_170627. Jürgen Gadau, Mark Lammers and Lukas Schrader acknowledge DFG grant SPP 1819 Rapid evolutionary adaptation (GA 661/4-1, SCHR 1554/3-1). We acknowledge the support of the Deutsche Forschungsgemeinschaft and Open Access Publishing Fund of University of Potsdam.

\section{Availability of data and materials}

Both genomes are available from the NCBI Genome database (PRJNA587428, A. ervi: SAMN13190903, L. fabarum: SAMN13190904). The bipaa webpage (https://bipaa.genouest.org) hosts the assemblies (https://bipaa.genouest.org/ sp/aphidius_ervi/download/genome/v3.1/ and https://bipaa.genouest.org/ sp/lysiphlebus_fabarum/download/genome/v1.0/), predicted genes, and annotations (https://bipaa.genouest.org/sp/aphidius_ervi/download/ annotation/ and https://bipaa.genouest.org/sp/lysiphlebus_fabarum/ download/annotation/v1.0/). Raw Illumina and PacBio sequence data used to construct genomes are available in NCBI SRA for both A. ervi (SAMN12878248) and L. fabarum (accessions SAMN10617865, SAMN10617866, SAMN10617867), and further detailed in Supplementary Tables 1 and 2. Venom protein data are available via ProteomeXchange (PXD015758; https://www.ebi.ac.uk/pride/archive/projects/PXD015758).

\section{Ethics approval and consent to participate}

No ethics approval was required for the collection or use of animals in this study.

\section{Consent for publication}

Not applicable.

\section{Competing interests}

Denis Tagu is a member of the editorial board of BMC Genomics.

\section{Author details}

${ }^{1}$ Department of Aquatic Ecology, Eawag, 8600 Dübendorf, Switzerland. ${ }^{2}$ Institute of Integrative Biology, ETH Zürich, 8092 Zürich, Switzerland. ${ }^{3}$ Institute of Biochemistry and Biology, University of Potsdam, 14476 Potsdam, Germany. ${ }^{4}$ Instituto de Ciencias Biológicas, Universidad de Talca, Talca, Chile. ${ }^{5}$ Centre for Molecular and Functional Ecology in Agroecosystems, Universidad de Talca, Talca, Chile. 'Laboratorio de Control Biológico, Instituto de Ciencias Biológicas, Universidad de Talca, Talca, Chile. ${ }^{7}$ IGEPP, Agrocampus Ouest, INRAE, Université de Rennes, 35650 Le Rheu, France. ${ }^{8}$ Université de Rennes 1, INRIA, CNRS, IRISA, 35000 Rennes, France. ${ }^{9}$ Institute for Evolution and Biodiversity, Universität Münster, Münster, Germany. ${ }^{10}$ Department of Ecology and Evolution, Université de Lausanne, 1015 Lausanne, Switzerland. ${ }^{11}$ Institute of Zoology, Universität zu Köln, 50674 Köln, Germany. ${ }^{12}$ Groningen Institute for Evolutionary Life Sciences, University of Groningen, Groningen, The Netherlands. ${ }^{13}$ Aix-Marseille Univ, CNRS, INP, Inst Neurophysiopathol, PINT, PFNT, Marseille, France.

${ }^{14}$ Department of Environmental Science, Policy, \& Management, University of California, Berkeley, Berkeley, CA 94720, USA. ${ }^{15}$ Université Côte d'Azur, INRAE, CNRS, ISA, Sophia Antipolis, France. ${ }^{16}$ Department of Sciences, University of Basilicata, 85100 Potenza, Italy. ${ }^{17}$ Department of Biology, Georgia Southern University, Statesboro, GA 30460, USA. ${ }^{18}$ Department of Environmental Systems Sciences, D-USYS, ETH Zürich, Zürich, Switzerland. ${ }^{19}$ INRAE, Sorbonne Université, CNRS, IRD, UPEC, Université Paris Diderot, Institute of Ecology and Environmental Sciences of Paris, iEES-Paris, F-78000 Versailles, France. ${ }^{20}$ Department of Biology, Earlham College, Richmond, IN 47374, USA. ${ }^{21}$ Department of Entomology, Max Planck Institute for Chemical Ecology, Jena, Germany.

\section{Received: 16 January 2020 Accepted: 30 April 2020}

\section{Published online: 29 May 2020}

\section{References}

1. Windsor DA. Controversies in parasitology: most of the species on earth are parasites. Int J Parasitol. 1998;28(12):1939-41.

2. Poulin R. Evolutionary ecology of parasites (second edition). Princeton: Princeton University Press; 2007.

3. Quicke DLJ. The braconid and Ichneumonid parasitoid wasps: biology, systematics, evolution and ecology; 2014.

4. Godfray HCJ. Parasitoids: behavioral and evolutionary ecology. Princeton: Princeton University Press; 1994.

5. Pennacchio F, Strand MR. Evolution of developmental strategies in parasitic hymenoptera. Annu Rev Entomol. 2006;51(1):233-58.

6. Heraty J. Parasitoid biodiversity and insect pest management. In: Insect Biodiversity. 2009.

7. Forbes AA, Bagley RK, Beer MA, Hippee AC, Widmayer HA. Quantifying the unquantifiable: why Hymenoptera, not Coleoptera, is the most speciose animal order. BMC Ecol. 2018;18(1):21.

8. Poelman EH, Bruinsma M, Zhu F, Weldegergis BT, Boursault AE, Jongema $Y$, van Loon JJA, Vet LEM, Harvey JA, Dicke M. Hyperparasitoids use herbivoreinduced plant volatiles to locate their parasitoid host. PLoS Biol. 2012;10(11): e1001435. 
9. Chen X-X, van Achterberg C. Systematics, phylogeny, and evolution of braconid wasps: 30 years of progress. Annu Rev Entomol. 2018;64:335-58.

10. Müller CB, Adriaanse ICT, Belshaw R, Godfray HCJ. The structure of an aphid-parasitoid community. J Anim Ecol. 2004;68(2):346-70.

11. Peters RS, Krogmann L, Mayer C, Donath A, Gunkel S, Meusemann K, Kozlov A, Podsiadlowski L, Petersen M, Lanfear R, et al. Evolutionary history of the Hymenoptera. Curr Biol. 2017;27(7):1013-8.

12. Vorburger C, Perlman SJ. The role of defensive symbionts in host-parasite coevolution. Biol Rev. 2018;93(4):1747-64.

13. Kraaijeveld AR, Van Alphen JJM, Godfray HCJ. The coevolution of host resistance and parasitoid virulence. Parasitology. 1998;116:S29-45.

14. Dupas S, Carton Y, Poiriè M. Genetic dimension of the coevolution of virulenceresistance in Drosophila - parasitoid wasp relationships. Heredity. 2003;90:84.

15. Boivin G, Hance T, Brodeur J. Aphid parasitoids in biological control. Can J Plant Sci. 2012;92:1-12

16. Heimpel GE, Mills NJ. Biological control : ecology and applications; 2017.

17. Henter HJ, Via S. The potential for coevolution in a host-parasitoid system. I. Genetic variation within an aphid population in susceptibility to a parasitic wasp. Evolution. 1995;49(3):427-38

18. Herzog J, Muller CB, Vorburger C. Strong parasitoid-mediated selection in experimental populations of aphids. Biol Lett. 2007;3(6):667-9.

19. Shi M, Chen X-X. Molecular phylogeny of the Aphidiinae (Hymenoptera: Braconidae) based on DNA sequences of 16S rRNA, 18S rDNA and ATPase 6 genes. EJE. 2005;102(2):133-8.

20. Łukasik P, Dawid MA, Ferrari J, Godfray HCJ. The diversity and fitness effects of infection with facultative endosymbionts in the grain aphid, Sitobion avenae. Oecologia. 2013;173(3):985-96.

21. Chau A, Mackauer M. Host-instar selection in the aphid parasitoid Monoctonus paulensis (Hymenoptera: Braconidae, Aphidiinae): a preference for small pea aphids. EJE. 2000;97(3):347-53.

22. Martinez AJ, Kim KL, Harmon JP, Oliver KM. Specificity of multi-modal aphid defenses against two rival parasitoids. PLoS One. 2016;11(5):e0154670.

23. Poirié $M$, Colinet $D$, Gatti J-L. Insights into function and evolution of parasitoid wasp venoms. Curr Opin Insect Sci. 2014;6:52-60

24. Colinet D, Anselme C, Deleury E, Mancini D, Poulain J, Azéma-Dossat C, Belghazi M, Tares S, Pennacchio F, Poirié M, et al. Identification of the main venom protein components of Aphidius ervi, a parasitoid wasp of the aphid model Acyrthosiphon pisum. BMC Genomics. 2014;15(1):342.

25. Burke GR, Strand MR. Systematic analysis of a wasp parasitism arsenal. Mol Ecol. 2014;23(4):890-901.

26. Strand MR. Teratocytes and their functions in parasitoids. Curr Opin Insect Sci. 2014;6:68-73.

27. Falabella $\mathrm{P}$, Tremblay E, Pennacchio F. Host regulation by the aphid parasitoid Aphidius envi: the role of teratocytes. Entomol Exp Appl. 2003;97(1):1-9.

28. Gross P. Insect behavioral and morphological defenses against parasitoids. Annu Rev Entomol. 1993;38(1):251-73.

29. Schmitz A, Anselme C, Ravallec M, Rebuf C, Simon J-C, Gatti J-L, Poirié M. The cellular immune response of the pea aphid to foreign intrusion and symbiotic challenge. PLoS One. 2012;7(7):e42114.

30. Oliver KM, Degnan PH, Burke GR, Moran NA. Facultative symbionts in aphids and the horizontal transfer of ecologically important traits. Annu Rev Entomol. 2010;55:247-66.

31. Oliver KM, Higashi CHV. Variations on a protective theme: Hamiltonella defensa infections in aphids variably impact parasitoid success. Curr Opin Insect Sci. 2018:32:1-7.

32. Shi M, Wang Z, Ye X, Xie H, Li F, Hu X, Wang Z, Yin C, Zhou Y, Gu Q, et al. The genomes of two parasitic wasps that parasitize the diamondback moth. BMC Genomics. 2019;20(1):893.

33. Tvedte ES, Walden KKO, McElroy KE, Werren JH, Forbes AA, Hood GR, Logsdon JM Jr, Feder JL, Robertson HM. Genome of the parasitoid wasp Diachasma alloeum, an emerging model for ecological speciation and transitions to asexual reproduction. Genome Biol Evol. 2019;11(10):2767-73.

34. Geib SM, Liang GH, Murphy TD, Sim SB. Whole genome sequencing of the Braconid parasitoid wasp Fopius arisanus, an important biocontrol agent of pest tepritid fruit flies. G3: Genes|Genomes|Genetics. 2017;7(8):2407-11.

35. Yin C, Li M, Hu J, Lang K, Chen Q, Liu J, Guo D, He K, Dong Y, Luo J, et al. The genomic features of parasitism, polyembryony and immune evasion in the endoparasitic wasp Macrocentrus cingulum. BMC Genomics. 2018;19:420.

36. Burke GR, Walden KKO, Whitfield JB, Robertson HM, Strand MR. Whole genome sequence of the parasitoid wasp Microplitis demolitor that harbors an endogenous virus mutualist. G3: Genes|Genomes|Genetics. 2018;8:2875-80.
37. Werren JH, Richards S, Desjardins CA, Niehuis O, Gadau J, Colbourne JK, Group TNGW. Functional and evolutionary insights from the genomes of three parasitoid Nasonia species. Science. 2010;327(5963):343-8.

38. Derocles SAP, Plantegenest M, Rasplus J-Y, Marie A, Evans DM, Lunt DH, Le Ralec A. Are generalist Aphidiinae (Hym. Braconidae) mostly cryptic species complexes? Syst Entomol. 2016;41(2):379-91.

39. Monticelli LS, Nguyen LTH, Amiens-Desneux E, Luo C, Lavoir A-V, Gatti J-L, Desneux N. The preference-performance relationship as a means of classifying parasitoids according to their specialization degree. Evol Appl. 2019;12:1626-40.

40. Kavallieratos NG, Tomanović Ž, Starý P, Athanassiou CG, Sarlis GP, et al. A survey of aphid parasitoids (Hymenoptera: Braconidae: Aphidiinae) of southeastern Europe and their aphid-plant associations. Appl Entomol Zool. 2004;39(3):527-63.

41. Rouchet $R$, Vorburger C. Experimental evolution of parasitoid infectivity on symbiont-protected hosts leads to the emergence of genotype specificity. Evolution. 2014;68(6):1607-16.

42. Dennis AB, Patel V, Oliver KM, Vorburger C. Parasitoid gene expression changes after adaptation to symbiont-protected hosts. Evolution. 2017; 71(11):2599-617.

43. Dion E, Zélé F, Simon JC, Outreman Y. Rapid evolution of parasitoids when faced with the symbiont-mediated resistance of their hosts. J Evol Biol. 2011;24(4):741-50.

44. Obbard DJ, Shi M, Longdon B, Dennis AB. A new family of segmented RNA viruses infecting animals. Virus Evolution. 2020;6(1):vez061.

45. Lüthi MN, Vorburger C, Dennis AB. A novel RNA virus in the parasitoid wasp Lysiphlebus fabarum: genomic structure, prevalence, and transmission. Viruses. 2020;12(1):59.

46. Zepeda-Paulo FA, Ortiz-Martínez SA, Figueroa CC, Lavandero B. Adaptive evolution of a generalist parasitoid: implications for the effectiveness of biological control agents. Evol Appl. 2013;6(6):983-99.

47. Zepeda-Paulo F, Lavandero B, Mahéo F, Dion E, Outreman Y, Simon J-C, Figueroa CC. Does sex-biased dispersal account for the lack of geographic and host-associated differentiation in introduced populations of an aphid parasitoid? Ecol Evol. 2015;5(11):2149-61.

48. Henry LM, Roitberg BD, Gillespie DR. Host-range evolution in Aphidius parasitoids: Fidelity, virulence and fitness trade-offs on an ancestral host. Evolution. 2008;62(3):689-99.

49. Hufbauer RA, Bogdanowicz SM, Harrison RG. The population genetics of a biological control introduction: mitochondrial DNA and microsatellie variation in native and introduced populations of Aphidus ervi, a parisitoid wasp. Mol Ecol. 2004;13(2):337-48.

50. Sandrock C, Schirrmeister B, Vorburger C. Evolution of reproductive mode variation and host associations in a sexual-asexual complex of aphid parasitoids. BMC Evol Biol. 2011;11(1):348.

51. Werren $\mathrm{JH}$, Baldo L, Clark ME. Wolbachia: master manipulators of invertebrate biology. Nat Rev Microbiol. 2008;6(10):741-51.

52. Belshaw R, Quicke DL. The cytogenetics of thelytoky in a predominantly asexual parasitoid wasp with covert sex. Genome National Research Council Canada. 2003;46(1):170-3.

53. Mateo Leach I, Pannebakker BA, Schneider MV, Driessen G, van de Zande L, Beukeboom LW. Thelytoky in Hymenoptera with Venturia canescens and Leptopilina clavipes as case studies. In: Schön I, Martens K, Dijk P, editors. Lost sex: the evolutionary biology of parthenogenesis. Dordrecht: Springer Netherlands; 2009. p. 347-75.

54. Sandrock C, Vorburger C. Single-locus recessive inheritance of asexual reproduction in a parasitoid wasp. Curr Biol. 2011;21(5):433-7.

55. Rasekh A, Michaud JP, Kharazi-Pakdel A, Allahyari H. Ant mimicry by an aphid parasitoid, Lysiphlebus fabarum. J Insect Sci. 2010;10:126.

56. Liepert C, Dettner K. Role of cuticular hydrocarbons of aphid parasitoids in their relationship to aphid-attending ants. J Chem Ecol. 1996;22(4): 695-707.

57. Liepert C, Dettner K. Recognition of aphid parasitoids by honeydewcollecting ants: the role of cuticular lipids in a chemical mimicry system. J Chem Ecol. 1993;19(10):2143-53.

58. Völkl W. Interactions between ants and aphid parasitoids: patterns and consequences for resource utilization. In: Dettner K, Bauer G, Völkl W, editors. Vertical food web interactions: evolutionary patterns and driving forces. Berlin: Springer Berlin Heidelberg; 1997. p. 225-40.

59. Völkl W. Aphids or their parasitoids: who actually benefits from antattendance? J Anim Ecol. 1992;61(2):273-81. 
60. Mapleson D, Garcia Accinelli G, Kettleborough G, Wright J, Clavijo BJ. KAT: a K-mer analysis toolkit to quality control NGS datasets and genome assemblies. Bioinformatics. 2016;33(4):574-6.

61. Ardila-Garcia AM, Umphrey GJ, Gregory TR. An expansion of the genome size dataset for the insect order Hymenoptera, with a first test of parasitism and eusociality as possible constraints. Insect Mol Biol. 2010;19(3):337-46.

62. Hanrahan SJ, Johnston JS. New genome size estimates of 134 species of arthropods. Chromosom Res. 2011;19(6):809-23.

63. Camacho C, Coulouris G, Avagyan V, Ma N, Papadopoulos J, Bealer K, Madden TL. BLAST+: architecture and applications. BMC Bioinformatics. 2009;10:421.

64. Laetsch DR, Blaxter ML. BlobTools: interrogation of genome assemblies [version 1; peer review: 2 approved with reservations]. F1000Research. 2017; 6(1287)

65. Wei S-J, Shi M, Sharkey MJ, van Achterberg C, Chen X-X. Comparative mitogenomics of Braconidae (Insecta: Hymenoptera) and the phylogenetic utility of mitochondrial genomes with special reference to Holometabolous insects. BMC Genomics. 2010;11:371.

66. Kurtz S, Phillippy A, Delcher AL, Smoot M, Shumway M, Antonescu C, Salzberg SL. Versatile and open software for comparing large genomes. Genome Biol. 2004:5(2):R12.

67. NCBI nr database, available from ftp.ncbi.n/m.nih.gov/blast/db/.

68. Ashburner M, Ball CA, Blake JA, Botstein D, Butler H, Cherry JM, Davis AP, Dolinski K, Dwight SS, Eppig JT, et al. Gene ontology: tool for the unification of biology. Nat Genet. 2000;25(1):25-9.

69. The Gene Ontology Consortium. The gene ontology resource: 20 years and still GOing strong. Nucleic Acids Res. 2018;47(D1):D330-8.

70. Seward EA, Kelly S. Dietary nitrogen alters codon bias and genome composition in parasitic microorganisms. Genome Biol. 2016;17(1):226

71. Ran W, Higgs PG. The influence of anticodon-codon interactions and modified bases on codon usage bias in bacteria. Mol Biol Evol. 2010;27(9): 2129-40.

72. Kudla G, Murray AW, Tollervey D, Plotkin JB. Coding-sequence determinants of gene expression in Escherichia coli. Science. 2009;324(5924):255.

73. Plotkin JB, Kudla G. Synonymous but not the same: the causes and consequences of codon bias. Nat Rev Genet. 2011;12(1):32-42.

74. Altenhoff AM, Levy J, Zarowiecki M, Tomiczek B, Warwick Vesztrocy A, Dalquen DA, Müller S, Telford MJ, Glover NM, Dylus D, et al. OMA standalone: orthology inference among public and custom genomes and transcriptomes. Genome Res.. 2019;29(7):1152-63.

75. Dorémus T, Urbach S, Jouan V, Cousserans F, Ravallec M, Demettre E, Wajnberg E, Poulain J, Azéma-Dossat C, Darboux I, et al. Venom gland extract is not required for successful parasitism in the polydnavirusassociated endoparasitoid Hyposoter didymator (Hym. Ichneumonidae) despite the presence of numerous novel and conserved venom proteins. Insect Biochem Mol Biol. 2013;43(3):292-307.

76. Liu N-Y, Wang J-Q, Zhang Z-B, Huang J-M, Zhu J-Y. Unraveling the venom components of an encyrtid endoparasitoid wasp Diversinervus elegans. Toxicon. 2017;136:15-26.

77. Van Vaerenbergh M, Debyser G, Devreese B, de Graaf DC. Exploring the hidden honeybee (Apis mellifera) venom proteome by integrating a combinatorial peptide ligand library approach with FTMS. J Proteome. 2014; 99:169-78.

78. Kim BY, Jin BR. Apolipophorin III from honeybees (Apis cerana) exhibits antibacterial activity. Comp Biochem Physiol B: Biochem Mol Biol. 2015;182:6-13.

79. Lee E, Helt GA, Reese JT, Munoz-Torres MC, Childers CP, Buels RM, Stein L, Holmes $1 H$, Elsik CG, Lewis SE. Web Apollo: a web-based genomic annotation editing platform. Genome Biol. 2013;14(8):R93.

80. Biolnformatics platform for agroecosystem arthropods (BIPAA) [https://bipaa. genouest.org].

81. Dunn NA, Unni DR, Diesh C, Munoz-Torres M, Harris NL, Yao E, Rasche H,

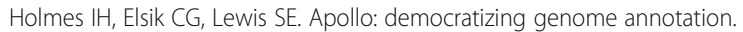
PLoS Comput Biol. 2019;15(2):e1006790.

82. Lemaitre B, Hoffman J. The host defence of Drosophila melanogaster. Annu Rev Immunol. 2007;25:697-743

83. Charroux B, Royet J. Drosophila immune response: from systemic antimicrobial peptide production in fat body cells to local defense in the intestinal tract. Fly. 2010;4(1):40-7.

84. Buchon N, Silverman N, Cherry S. Immunity in Drosophila melanogaster from microbial recognition to whole-organism physiology. Nat Rev Immunol. 2014;14:796.
85. Bischoff V, Vignal C, Boneca IG, Michel T, Hoffmann JA, Royet J. Function of the Drosophila pattern-recognition receptor PGRP-SD in the detection of gram-positive bacteria. Nat Immunol. 2004;5(11):1175-80.

86. Smoyer LK, Dorer DR, Nickerson KW, Christensen AC. Phenotype of the Triplo-lethal locus of Drosophila melanogaster and its suppression by hyperoxia. Genet Res. 2003;82(3):163-70.

87. Andrade López JM, Lanno SM, Auerbach JM, Moskowitz EC, Sligar LA, Wittkopp PJ, Coolon JD. Genetic basis of octanoic acid resistance in Drosophila sechellia: functional analysis of a fine-mapped region. Mol Ecol. 2017:26(4):1148-60.

88. Schmitt-Engel C, Schultheis D, Schwirz J, Ströhlein N, Troelenberg N, Majumdar U, Dao VA, Grossmann D, Richter T, Tech M, et al. The iBeetle large-scale RNAi screen reveals gene functions for insect development and physiology. Nat Commun. 2015;6:7822.

89. Greenwood JM, Milutinovic B, Peuss R, Behrens S, Esser D, Rosenstiel P, Schulenburg H, Kurtz J. Oral immune priming with Bacillus thuringiensis induces a shift in the gene expression of Tribolium castaneum larvae. BMC Genomics. 2017;18(1):329.

90. Vilcinskas A, Vogel H. Seasonal phenotype-specific transcriptional reprogramming during metamorphosis in the European map butterfly Araschnia levana. Ecol Evol. 2016;6(11):3476-85.

91. Smith CR, Morandin C, Noureddine M, Pant S. Conserved roles of Osiris genes in insect development, polymorphism and protection. J Evol Biol. 2018;31(4):516-29.

92. Li Y, Zhang R, Liu S, Donath A, Peters RS, Ware J, Misof B, Niehuis O, Pfrender ME, Zhou X. The molecular evolutionary dynamics of oxidative phosphorylation (OXPHOS) genes in Hymenoptera. BMC Evol Biol. 2017; 17(1):269.

93. Nouhaud P, Gautier M, Gouin A, Jaquiéry J, Peccoud J, Legeai F, Mieuzet L, Smadja CM, Lemaitre C, Vitalis R, et al. Identifying genomic hotspots of differentiation and candidate genes involved in the adaptive divergence of pea aphid host races. Mol Ecol. 2018;27(16):3287-300.

94. Comeault AA, Serrato-Capuchina A, Turissini DA, McLaughlin PJ, David JR, Matute DR. A nonrandom subset of olfactory genes is associated with host preference in the fruit fly Drosophila orena. Evol Lett. 2017;1(2):73-85.

95. Vieira FG, Forêt $\mathrm{S}, \mathrm{He} X$, Rozas J, Field LM, Zhou J-J. Unique features of odorant-binding proteins of the parasitoid wasp Nasonia vitripennis revealed by genome annotation and comparative analyses. PLoS One. 2012;7(8): e43034.

96. Ahmed T, Zhang T, Wang Z, He K, Bai S. Gene set of chemosensory receptors in the polyembryonic endoparasitoid Macrocentrus cingulum. Sci Rep. 2016;6:24078.

97. Robertson HM, Gadau J, Wanner KW. The insect chemoreceptor superfamily of the parasitoid jewel wasp Nasonia vitripennis. Insect Mol Biol. 2010;19(s1): 121-36.

98. Kang Z-W, Tian H-G, Liu F-H, Liu X, Jing X-F, Liu T-X. Identification and expression analysis of chemosensory receptor genes in an aphid endoparasitoid Aphidius gifuensis. Sci Rep. 2017;7(1):3939.

99. Harrison MC, Jongepier E, Robertson HM, Arning N, Bitard-Feildel T, Chao H, Childers CP, Dinh H, Doddapaneni H, Dugan S, et al. Hemimetabolous genomes reveal molecular basis of termite eusociality. Nat Ecol Evol. 2018; 2(3):557-66.

100. Geuverink E, Verhulst EC, van Leussen M, van de Zande L, Beukeboom LW. Maternal provision of non-sex-specific transformer messenger RNA in sex determination of the wasp Asobara tabida. Insect Mol Biol. 2018;27(1):99-109.

101. Matthey-Doret C, van der Kooi CJ, Jeffries DL, Bast J, Dennis AB, Vorburger C, Schwander T. Mapping of multiple complementary sex determination loci in a parasitoid wasp. Genome Biol Evol. 2019;11:2954-62 (evz219).

102. Heimpel GE, de Boer JG. Sex determination in the Hymenoptera. Annu Rev Entomol. 2007:53(1):209-30.

103. Yamamoto D. Brain sex differences and function of the fruitless gene in Drosophila. J Neurogenet. 2008;22(3):309-32.

104. Bell LR, Maine EM, Schedl P, Cline TW. Sex-lethal, a Drosophila sex determination switch gene, exhibits sex-specific RNA splicing and sequence similarity to RNA binding proteins. Cell. 1988;55(6):1037-46.

105. Sharma A, Heinze SD, Wu Y, Kohlbrenner T, Morilla I, Brunner C, Wimmer EA van de Zande L, Robinson MD, Beukeboom LW, et al. Male sex in houseflies is determined by Mdmd, a paralog of the generic splice factor gene CWC22. Science. 2017;356(6338):642.

106. Jeltsch A, Jurkowska RZ. New concepts in DNA methylation. Trends Biochem Sci. 2014;39(7):310-8. 
107. Provataris P, Meusemann K, Niehuis O, Grath S, Misof B. Signatures of DNA methylation across insects suggest reduced DNA methylation levels in holometabola. Genome Biol Evol. 2018;10(4):1185-97.

108. Bewick AJ, Vogel KJ, Moore AJ, Schmitz RJ. Evolution of DNA methylation across insects. Mol Biol Evol. 2017;34(3):654-65.

109. Geuverink E. Parental and endosymbiont effects on sex determination in haplodiploid wasps : who is in control? Groningen: University of Groningen; 2017.

110. Huang H, Wu P, Zhang S, Shang Q, Yin H, Hou Q, Zhong J, Guo X. DNA methylomes and transcriptomes analysis reveal implication of host DNA methylation machinery in BmNPV proliferation in Bombyx mori. BMC Genomics. 2019;20(1):736.

111. Vilcinskas A. The impact of parasites on host insect epigenetics. Adv Insect Physiol. 2017;53:145-65.

112. Vilcinskas A. The role of epigenetics in host-parasite coevolution: lessons from the model host insects Galleria mellonella and Tribolium castaneum. Zoology. 2016;119(4):273-80.

113. Van Oss SB, Carvunis A-R. De novo gene birth. PLoS Genet. 2019;15(5): e1008160.

114. Gold DA, Katsuki T, Li Y, Yan X, Regulski M, Ibberson D, Holstein T, Steele RE, Jacobs DK, Greenspan RJ. The genome of the jellyfish Aurelia and the evolution of animal complexity. Nat Ecol Evol. 2018;3:96-104.

115. Drosophila 12 Genomes C, Clark AG, Eisen MB, Smith DR, Bergman CM, Oliver B, Markow TA, Kaufman TC, Kellis M, Gelbart W, et al. Evolution of genes and genomes on the Drosophila phylogeny. Nature. 2007;450:203.

116. Maumus F, Fiston-Lavier A-S, Quesneville H. Impact of transposable elements on insect genomes and biology. Curr Opin Insect Sci. 2015; 7(Complete):30-6.

117. Barahimipour R, Strenkert D, Neupert J, Schroda M, Merchant SS, Bock R. Dissecting the contributions of GC content and codon usage to gene expression in the model alga Chlamydomonas reinhardtii. Plant J. 2015;84(4): 704-17.

118. Foerstner KU, von Mering C, Hooper SD, Bork P. Environments shape the nucleotide composition of genomes. EMBO Rep. 2005;6(12):1208.

119. Šmarda $P$, Bureš $P$, Horová L, Leitch IJ, Mucina L, Pacini E, Tichý L, Grulich $V$, Rotreklová O. Ecological and evolutionary significance of genomic GC content diversity in monocots. Proc Natl Acad Sci. 2014;111(39):E4096.

120. Li Y, Park H, Smith TE, Moran NA. Gene family evolution in the pea aphid based on chromosome-level genome assembly. Mol Biol Evol. 2019;36(10): 2143-56.

121. Almpanis A, Swain M, Gatherer D, McEwan N. Correlation between bacterial $\mathrm{G}+\mathrm{C}$ content, genome size and the $\mathrm{G}+\mathrm{C}$ content of associated plasmids and bacteriophages. Microbial Genomics. 2018;4(4).

122. McCutcheon JP, McDonald BR, Moran NA. Origin of an alternative genetic code in the extremely small and GC-rich genome of a bacterial symbiont. PLoS Genet. 2009;5(7):e1000565.

123. Veleba A, Zedek F, Šmerda J, Horová L, Šmarda P, Bureš P. Evolution of genome size and genomic GC content in carnivorous holokinetics (Droseraceae). Ann Bot. 2016;119(3):409-16.

124. Vinogradov AE. Genome size and GC-percent in vertebrates as determined by flow cytometry: the triangular relationship. Cytometry. 1998;31(2):100-9.

125. Mugal CF, Arndt PF, Holm L, Ellegren H. Evolutionary consequences of DNA methylation on the GC content in vertebrate genomes. G3: Genes|Genomes|Genetics. 2015;5(3):441.

126. Acquisti C, Elser JJ, Kumar S. Ecological nitrogen limitation shapes the DNA composition of plant genomes. Mol Biol Evol. 2009;26(5):953-6.

127. Romero IG, Ruvinsky I, Gilad Y. Comparative studies of gene expression and the evolution of gene regulation. Nat Rev Genet. 2012;13(7):505-16.

128. Rao YS, Chai XW, Wang ZF, Nie QH, Zhang XQ. Impact of GC content on gene expression pattern in chicken. Genet Sel Evol. 2013;45(1):9-9.

129. Kudla G, Lipinski L, Caffin F, Helwak A, Zylicz M. High guanine and cytosine content increases mRNA levels in mammalian cells. PLoS Biol. 2006;4(6): e180.

130. Chaney JL, Clark PL. Roles for synonymous codon usage in protein biogenesis. Annu Rev Biophys. 2015;44(1):143-66.

131. Galtier N, Roux C, Rousselle M, Romiguier J, Figuet E, Glémin S, Bierne N, Duret L. Codon usage bias in animals: disentangling the effects of natural selection, effective population size, and GC-biased gene conversion. Mol Biol Evol. 2018;35(5):1092-103.

132. Rocha EPC, Danchin A. Base composition bias might result from competition for metabolic resources. Trends Genet. 2002;18(6):291-4.
133. Cheng R-X, Meng L, Mills NJ, Li B. Host preference between symbiotic and aposymbiotic Aphis fabae, by the aphid parasitoid, Lysiphlebus ambiguus. J Insect Sci. 2011;11:81.

134. Pennacchio F, Fanti P, Falabella P, Digilio MC, Bisaccia F, Tremblay E. Development and nutrition of the braconid wasp, Aphidius ervi in aposymbiotic host aphids. Arch Insect Biochem Physiol. 1999;40(1):53-63.

135. Miao X, Huang Y, Zhu X, Ding D. A comparative study on development and reproduction of the parasitoid Lysiphlebus japonicus (Hymenoptera: Aphidiidae) in symbiotic and aposymbiotic host aphids. Appl Entomol Zool. 2004;39(2):243-8.

136. Bentele K, Saffert $P$, Rauscher $R$, Ignatova Z, Blüthgen N. Efficient translation initiation dictates codon usage at gene start. Mol Syst Biol. 2013;9:675.

137. Behura SK, Severson DW. Codon usage bias: causative factors, quantification methods and genome-wide patterns: with emphasis on insect genomes. Biol Rev. 2013;88(1):49-61.

138. Powell JR, Moriyama EN. Evolution of codon usage bias in Drosophila. Proc Natl Acad Sci. 1997;94(15):7784.

139. Soanes DM, Talbot NJ. Comparative genome analysis reveals an absence of leucine-rich repeat pattern-recognition receptor proteins in the kingdom Fungi. PLoS One. 2010;5(9):e12725.

140. Takeda K, Akira S. Toll-like receptors in innate immunity. Int Immunol. 2005; 17(1):1-14.

141. Zhao C, Escalante Lucio N, Chen H, Benatti Thiago R, Qu J, Chellapilla S, Waterhouse Robert M, Wheeler D, Andersson Martin N, Bao R, et al. A massive expansion of effector genes underlies gall-formation in the wheat pest Mayetiola destructor. Curr Biol. 2015;25(5):613-20.

142. Singh R, Bassett E, Chakravarti A, Parthun MR. Replication-dependent histone isoforms: a new source of complexity in chromatin structure and function. Nucleic Acids Res. 2018;46(17):8665-78.

143. Kuroki S, Matoba S, Akiyoshi M, Matsumura Y, Miyachi H, Mise N, Abe K, Ogura A, Wilhelm D, Koopman P, et al. Epigenetic regulation of mouse sex determination by the histone demethylase Jmid1a. Science. 2013;341(6150):1106.

144. Moreau S, Asgari S. Venom proteins from parasitoid wasps and their biological functions. Toxins. 2015;7(7):2385.

145. Falabella P, Riviello L, Caccialupi P, Rossodivita T, Teresa Valente M, Luisa De Stradis M, Tranfaglia A, Varricchio P, Gigliotti S, Graziani F, et al. A Y-glutamyl transpeptidase of Aphidius ervi venom induces apoptosis in the ovaries of host aphids. Insect Biochem Mol Biol. 2007:37(5):453-65.

146. Mathé-Hubert H, Colinet D, Deleury E, Belghazi M, Ravallec M, Poulain J, Dossat C, Poirié M, Gatti J-L. Comparative venomics of Psyttalia lounsburyi and $P$. concolor, two olive fruit fly parasitoids: a hypothetical role for a $\mathrm{GH} 1$ ß-glucosidase. Sci Rep. 2016;6(1):35873.

147. Robertson HM, Waterhouse RM, Walden KKO, Ruzzante L, Reijnders MJMF, Coates BS, Legeai F, Gress JC, Biyiklioglu S, Weaver DK, et al. Genome sequence of the wheat stem sawfly, Cephus cinctus, representing an earlybranching lineage of the Hymenoptera, illuminates evolution of hymenopteran chemoreceptors. Genome Biol Evol. 2018;10(11):2997-3011.

148. Los DA, Murata N. Structure and expression of fatty acid desaturases. Biochim Biophys Acta (BBA) Lipids and Lipid Metab. 1998;1394(1):3-15.

149. Sperling P, Ternes P, Zank TK, Heinz E. The evolution of desaturases. Prostaglandins Leukot Essent Fat Acids. 2003;68(2):73-95.

150. Helmkampf M, Cash E, Gadau J. Evolution of the insect desaturase gene family with an emphasis on social Hymenoptera. Mol Biol Evol. 2015;32(2):456-71.

151. Legeai F, Shigenobu S, Gauthier JP, Colbourne J, Rispe C, Collin O, Richards S, Wilson ACC, Murphy T, Tagu D. AphidBase: a centralized bioinformatic resource for annotation of the pea aphid genome. Insect Mol Biol. 2010; 19(Suppl 2(0 2)):5-12.

152. Gerardo NM, Altincicek B, Anselme C, Atamian H, Barribeau SM, de Vos M, Duncan EJ, Evans JD, Gabaldón T, Ghanim M, et al. Immunity and other defenses in pea aphids, Acyrthosiphon pisum. Genome Biol. 2010;11(2):R21.

153. Scarborough CL, Ferrari J, Godfray HCJ. Aphid protected from pathogen by endosymbiont. Science. 2005;310(5755):1781.

154. Leclair M, Pons I, Mahéo F, Morlière S, Simon J-C, Outreman Y. Diversity in symbiont consortia in the pea aphid complex is associated with large phenotypic variation in the insect host. Evol Ecol. 2016;30(5):925-41.

155. Guo J, Hatt S, He K, Chen J, Francis F, Wang Z. Nine facultative endosymbionts in aphids. A review. J Asia Pac Entomol. 2017;20(3):794-801.

156. Nishide Y, Kageyama D, Yokoi K, Jouraku A, Tanaka H, Futahashi R, Fukatsu T. Functional crosstalk across IMD and toll pathways: insight into the evolution of incomplete immune cascades. Proc R Soc B Biol Sci. 2019; 286(1897):20182207. 
157. Dennis AB, Käch H, Vorburger C. Dual RNA-seq in an aphid parasitoid reveals plastic and evolved adaptation. BioRxiv. in revision.

158. Tougeron K, Brodeur J, Le Lann C, van Baaren J. How climate change affects the seasonal ecology of insect parasitoids. Ecol Entomol. 2020;45:167-81.

159. Tougeron K, Le Lann C, Brodeur J, van Baaren J. Are aphid parasitoids from mild winter climates losing their winter diapause? Oecologia. 2017;183(3): 619-29.

160. Ballesteros Gl, Gadau J, Legeai F, Gonzalez-Gonzalez A, Lavandero B, Simon J-C, Figueroa CC. Expression differences in Aphidius ervi (Hymenoptera: Braconidae) females reared on different aphid host species. PeerJ. 2017;5: e3640.

161. Sepúlveda D, Zepeda-Paulo F, Ramírez C, Lavandero B, Figueroa C. Loss of host fidelity in highly inbred populations of the parasitoid wasp Aphidius ervi (Hymenoptera: Braconidae); 2016.

162. Hebert PDN, Cywinska A, Ball SL, de Waard JR. Biological identifications through DNA barcodes. Proc Biol Sci. 2003;270(1512):313-21.

163. Peccoud J, Simon J-C, MCLaughlin HJ, Moran NA. Post-Pleistocene radiation of the pea aphid complex revealed by rapidly evolving endosymbionts. Proc Natl Acad Sci. 2009;106(38):16315.

164. Andrews S, Krueger F, Segonds-Pichon A, Biggins L, Wingett S, Ewels P: FastQC: a quality control tool for high throughput sequence data. Available online at: http://www.bioinformatics.babraham.ac.uk/projects/fastqc. 2010.

165. Bolger AM, Lohse M, Usadel B. Trimmomatic: a flexible trimmer for Illumina sequence data. Bioinformatics. 2014;30(15):2114-20.

166. Leggett RM, Clavijo BJ, Clissold L, Clark MD, Caccamo M. NextClip: an analysis and read preparation tool for Nextera long mate pair libraries. Bioinformatics. 2014;30(4):566-8.

167. Kajitani R, Toshimoto K, Noguchi H, Toyoda A, Ogura Y, Okuno M, Yabana M, Harada M, Nagayasu E, Maruyama H, et al. Efficient de novo assembly of highly heterozygous genomes from whole-genome shotgun short reads. Genome Res. 2014;24(8):1384-95.

168. Luo R, Liu B, Xie Y, Li Z, Huang W, Yuan J, He G, Chen Y, Pan Q, Liu Y, et al. SOAPdenovo2: an empirically improved memory-efficient short-read de novo assembler. GigaScience. 2012;1:18.

169. Boetzer M, Pirovano W. SSPACE-LongRead: scaffolding bacterial draft genomes using long read sequence information. BMC Bioinformatics. 2014; 15(1):211.

170. Hackl T, Hedrich R, Schultz J, Förster F. Proovread: large-scale high-accuracy PacBio correction through iterative short read consensus. Bioinformatics. 2014;30(21):3004-11.

171. Koren S, Walenz BP, Berlin K, Miller JR, Bergman NH, Phillippy AM. Canu: scalable and accurate long-read assembly via adaptive k-mer weighting and repeat separation. Genome Res. 2017;27(5):722-36.

172. Walker BJ, Abeel T, Shea T, Priest M, Abouelliel A, Sakthikumar S, Cuomo CA, Zeng Q, Wortman J, Young SK, et al. Pilon: an integrated tool for comprehensive microbial variant detection and genome assembly improvement. PLoS One. 2014;9(11):e112963.

173. Li H, Durbin R. Fast and accurate short read alignment with BurrowsWheeler transform. Bioinformatics. 2009:25(14)1754-60.

174. Wang J, Wurm Y, Nipitwattanaphon M, Riba-Grognuz O, Huang Y-C, Shoemaker D, Keller L. A Y-like social chromosome causes alternative colony organization in fire ants. Nature. 2013;493(7434):664-8.

175. Purcell J, Brelsford A, Wurm Y, Perrin N, Chapuisat M. Convergent genetic architecture underlies social organization in ants. Curr Biol. 2014;24(22): 2728-32.

176. Aljanabi S, Martinez I. Universal and rapid salt-extraction of high quality genomic DNA for PCR-based techniques. Nucleic Acids Res. 1997;25:4692-3.

177. Parchman TL, Gompert Z, Mudge J, Schilkey FD, Benkman CW, Buerkle CA. Genome-wide association genetics of an adaptive trait in lodgepole pine. Mol Ecol. 2012;21(12):2991-3005.

178. Peterson BK, Weber JN, Kay EH, Fisher HS, Hoekstra HE. Double digest RADseq: an inexpensive method for de novo SNP discovery and genotyping in model and non-model species. PLoS One. 2012;7(5):e37135.

179. Catchen JM, Amores A, Hohenlohe P, Cresko W, Postlethwait JH. Stacks: building and genotyping loci de novo from short-read sequences. G3: Genes, Genomes, Genetics. 2011;1(3):171-82.

180. Langmead B, Salzberg SL. Fast gapped-read alignment with bowtie 2. Nat Methods. 2012;9(4):357-9.

181. Li H, Handsaker B, Wysoker A, Fennell T, Ruan J, Homer N, Marth G, Abecasis $\mathrm{G}$, Durbin R. The sequence alignment/map format and SAMtools. Bioinformatics. 2009;25(16):2078-9.
182. Li H. A statistical framework for SNP calling, mutation discovery, association mapping and population genetical parameter estimation from sequencing data. Bioinformatics (Oxford, England). 2011;27(21): 2987-93.

183. Danecek P, Auton A, Abecasis G, Albers CA, Banks E, DePristo MA, Handsaker RE, Lunter G, Marth GT, Sherry ST, et al. The variant call format and VCFtools. Bioinformatics. 2011;27(15):2156-8.

184. Gadau J. Phase-unknown linkage mapping in ants. Cold Spring Harb Protoc. 2009;2009(7):pdb prot5251.

185. Wu Y, Bhat PR, Close TJ, Lonardi S. Efficient and accurate construction of genetic linkage maps from the minimum spanning tree of a graph. PLoS Genet. 2008;4(10):e1000212.

186. Tang H, Zhang X, Miao C, Zhang J, Ming R, Schnable J, Schnable P, Lyons E, Lu J. ALLMAPS: robust scaffold ordering based on multiple maps. Genome Biol. 2015;16(1):3.

187. Simão FA, Waterhouse RM, loannidis P, Kriventseva EV, Zdobnov EM. BUSCO: assessing genome assembly and annotation completeness with single-copy orthologs. Bioinformatics. 2015;31(19):3210-2.

188. Holt C, Yandell M. MAKER2: an annotation pipeline and genome-database management tool for second-generation genome projects. BMC Bioinformatics. 2011;12(1):491.

189. Keller O, Kollmar M, Stanke M, Waack S. A novel hybrid gene prediction method employing protein multiple sequence alignments. Bioinformatics. 2011;27(6):757-63.

190. Korf I. Gene finding in novel genomes. BMC Bioinformatics. 2004;5(1):59.

191. Grabherr MG, Haas BJ, Yassour M, Levin JZ, Thompson DA, Amit I, Adiconis X, Fan L, Raychowdhury R, Zeng Q, et al. Full-length transcriptome assembly from RNA-Seq data without a reference genome. Nat Biotechnol. 2011;29(7): 644-52.

192. Hall B, DeRego T, Geib S: GAG: the Genome Annotation Generator (version 1.0) [Software]. Available from http://genomeannotation.github.io/GAG. 2014.

193. Dobin A, Davis CA, Schlesinger F, Drenkow J, Zaleski C, Jha S, Batut $P$, Chaisson M, Gingeras TR. STAR: ultrafast universal RNA-seq aligner. Bioinformatics. 2013;29(1):15-21.

194. Emanuelsson O, Brunak $\mathrm{S}$, von Heijne $\mathrm{G}$, Nielsen $\mathrm{H}$. Locating proteins in the cell using TargetP, SignalP and related tools. Nat Protoc. 2007;2(4):953-71.

195. Nielsen H. Predicting secretory proteins with SignalP, available at: http:// www.cbs.dtu.dk/services/SignalP/. In: Kihara D, editor. Protein function prediction: methods and protocols. New York: Springer New York; 2017. p. 59-73.

196. Flutre T, Duprat E, Feuillet C, Quesneville H. Considering transposable element diversification in de novo annotation approaches. PLoS One. 2011; 6(1):e16526.

197. Bao Z, Eddy SR. Automated de novo identification of repeat sequence families in sequenced genomes. Genome Res. 2002;12(8):1269-76.

198. Quesneville H, Bergman CM, Andrieu O, Autard D, Nouaud D, Ashburner M, Anxolabehere D. Combined evidence annotation of transposable elements in genome sequences. PLoS Comput Biol. 2005;1(2):e22.

199. Edgar RC, Myers EW. PILER: identification and classification of genomic repeats. Bioinformatics. 2005;21:i152-8.

200. Huang X. On global sequence alignment. Comput Appl Biosci. 1994;10(3): 227-35.

201. Jurka J. Repeats in genomic DNA: mining and meaning. Curr Opin Struct Biol. 1998;8(3):333-7.

202. Bao W, Kojima KK, Kohany O. Repbase update, a database of repetitive elements in eukaryotic genomes. Mob DNA. 2015;6(1):11.

203. Mistry J, Finn RD, Eddy SR, Bateman A, Punta M. Challenges in homology search: HMMER3 and convergent evolution of coiled-coil regions. Nucleic Acids Res. 2013;41(12):e121.

204. Hoede C, Arnoux S, Moisset M, Chaumier T, Inizan O, Jamilloux V, Quesneville H. PASTEC: an automatic transposable element classification tool. PLoS One. 2014;9(5):e91929.

205. Smit A, Hubley R, Green P. RepeatMasker Open-4.0; 2013-2015.

206. Kohany O, Gentles AJ, Hankus L, Jurka J. Annotation, submission and screening of repetitive elements in Repbase: RepbaseSubmitter and Censor. BMC Bioinformatics. 2006;7(1):474.

207. Benson G. Tandem repeats finder: a program to analyze DNA sequences. Nucleic Acids Res. 1999;27(2):573-80.

208. Kolpakov R, Bana G, Kucherov G. mreps: efficient and flexible detection of tandem repeats in DNA. Nucleic Acids Res. 2003;31(13):3672-8. 
209. Goubert C, Modolo L, Vieira C, ValienteMoro C, Mavingui P, Boulesteix M. De novo assembly and annotation of the Asian tiger mosquito (Aedes albopictus) repeatome with dnaPipeTE from raw genomic reads and comparative analysis with the yellow fever mosquito (Aedes aegypti). Genome Biol Evol. 2015;7(4):1192-205.

210. Sun Y: sscu: strength of selected codon usage. Edited by 2.6.0 Rpv; 2016.

211. Charif D, Lobry JR. SeqinR 1.0-2: a contributed package to the R project for statistical computing devoted to biological sequences retrieval and analysis. In: Bastolla U, Porto M, Roman HE, Vendruscolo M, editors. Structural approaches to sequence evolution: molecules, networks, populations. Berlin: Springer Berlin Heidelberg; 2007. p. 207-32.

212. Wickham H. Reshaping data with the reshape package. J Stat Softw. 2007; 1(2007):12.

213. Wickham H. Ggplot2 elegant graphics for data analysis. New York: Springer; 2009

214. Kassambara A, Mundt F: Factoextra: extract and visualize the results of multivariate data analyses. In. Edited by package r; 2016.

215. Love M, Huber W, Anders S. Moderated estimation of fold change and dispersion for RNA-seq data with DESeq2. Genome Biol. 2014;15(12):550.

216. Emms DM, Kelly S. OrthoFinder: solving fundamental biases in whole genome comparisons dramatically improves orthogroup inference accuracy. Genome Biol. 2015;16(1):157.

217. Perkins DN, Pappin DJC, Creasy DM, Cottrell JS. Probability-based protein identification by searching sequence databases using mass spectrometry data. Electrophoresis. 1999;20(18):3551-67.

218. Finn RD, Bateman A, Clements J, Coggill P, Eberhardt RY, Eddy SR, Heger A, Hetherington $\mathrm{K}$, Holm L, Mistry J, et al. Pfam: the protein families database. Nucleic Acids Res. 2013;42(D1):D222-30.

219. Edgar RC. MUSCLE: a multiple sequence alignment method with reduced time and space complexity. BMC Bioinformatics. 2004;5(1):113.

220. Edgar RC. MUSCLE: multiple sequence alignment with high accuracy and high throughput. Nucleic Acids Res. 2004;32(5):1792-7.

221. Guindon S, Dufayard J-F, Lefort V, Anisimova M, Hordijk W, Gascuel O. New algorithms and methods to estimate maximum-likelihood phylogenies: assessing the performance of PhyML 3.0. Syst Biol. 2010;59(3):307-21.

222. Lefort $\mathrm{V}$, Longueville J-E, Gascuel O. SMS: smart model selection in PhyML Mol Biol Evol. 2017;34(9):2422-4.

223. Keilwagen J, Wenk M, Erickson JL, Schattat MH, Grau J, Hartung F. Using intron position conservation for homology-based gene prediction. Nucleic Acids Res. 2016:44(9):e89.

224. De Gregorio E, Spellman PT, Rubin GM, Lemaitre B. Genome-wide analysis of the Drosophila immune response by using oligonucleotide microarrays. Proc Natl Acad Sci. 2001;98(22):12590.

225. De Gregorio E, Spellman PT, Tzou P, Rubin GM, Lemaitre B. The toll and Imd pathways are the major regulators of the immune response in Drosophila. EMBO J. 2002;21(11):2568-79.

226. Wheeler TJ, Eddy SR. nhmmer: DNA homology search with profile HMMs. Bioinformatics. 2013;29(19):2487-9.

227. Altschul SF, Gish W, Miller W, Myers EW, Lipman DJ. Basic local alignment search tool. J Mol Biol. 1990;215(3):403-10

228. Katoh K, Standley DM. MAFFT multiple sequence alignment software version 7: improvements in performance and usability. Mol Biol Evol. 2013, 30(4):772-80.

229. Price MN, Dehal PS, Arkin AP. FastTree: computing large minimum evolution trees with profiles instead of a distance matrix. Mol Biol Evol. 2009;26(7):1641-50.

230. Miller MA, Schwartz T, Pickett BE, He S, Klem EB, Scheuermann RH, Passarotti M, Kaufman S, O'Leary MA. A RESTful API for access to phylogenetic tools via the CIPRES science gateway. Evol Bioinformatics Online. 2015;11:43-8.

231. Gibson JD, Niehuis O, Verrelli BC, Gadau J. Contrasting patterns of selective constraints in nuclear-encoded genes of the oxidative phosphorylation pathway in holometabolous insects and their possible role in hybrid breakdown in Nasonia. Heredity. 2010;104:310.

232. Porcelli D, Barsanti P, Pesole G, Caggese C. The nuclear OXPHOS genes in insecta: a common evolutionary origin, a common cis-regulatory motif, a common destiny for gene duplicates. BMC Evol Biol. 2007;7:215.

233. Altschul SF, Madden TL, Schäffer AA, Zhang J, Zhang Z, Miller W, Lipman DJ. Gapped BLAST and PSI-BLAST: a new generation of protein database search programs. Nucleic Acids Res. 1997;25(17):3389-402.

234. Keller O, Odronitz F, Stanke M, Kollmar M, Waack S. Scipio: using protein sequences to determine the precise exon/intron structures of genes and their orthologs in closely related species. BMC Bioinformatics. 2008;9:278.
235. Slater GSC, Birney E. Automated generation of heuristics for biological sequence comparison. BMC Bioinformatics. 2005;6(1):31.

236. Haas BJ, Salzberg SL, Zhu W, Pertea M, Allen JE, Orvis J, White O, Buell CR, Wortman JR. Automated eukaryotic gene structure annotation using EVidenceModeler and the program to assemble spliced alignments. Genome Biol. 2008;9(1):R7.

237. Eddy SR. Profile hidden Markov models. Bioinformatics. 1998;14(9):755-63.

238. Price MN, Dehal PS, Arkin AP. FastTree 2 - approximately maximumlikelihood trees for large alignments. PLoS One. 2010;5(3):e9490.

239. Letunic I, Bork P. Interactive tree of life (iTOL) v4: recent updates and new developments. Nucleic Acids Res. 2019:47(W1):W256-9.

240. Wang Y, Jorda M, Jones PL, Maleszka R, Ling X, Robertson HM, Mizzen CA Peinado MA, Robinson GE. Functional CpG methylation system in a social insect. Science. 2006;314(5799):645

\section{Publisher's Note}

Springer Nature remains neutral with regard to jurisdictional claims in published maps and institutional affiliations.
Ready to submit your research? Choose BMC and benefit from:

- fast, convenient online submission

- thorough peer review by experienced researchers in your field

- rapid publication on acceptance

- support for research data, including large and complex data types

- gold Open Access which fosters wider collaboration and increased citations

- maximum visibility for your research: over $100 \mathrm{M}$ website views per year

At $\mathrm{BMC}$, research is always in progress.

Learn more biomedcentral.com/submissions 